\title{
PROYECTO PARA LA VOZ “ORDENAMIENTO JURÍDICO” DE UN DICCIONARIO
}

\author{
Riccardo Guastini \\ Universidad de Génova
}

\begin{abstract}
RESUMEN. En este trabajo el autor se ocupa de las siguientes cuestiones sobre los ordenamientos jurídicos: 1 . Concepciones. 1.1. El ordenamiento como conjunto de normas. 1.2. El ordenamiento como complejo de instituciones. 2. Componentes. 2.1. Normas originarias y normas derivadas. 2.2. Normas formuladas y normas implícitas. 2.3. Normas primarias y normas secundarias. 2.4. Normas válidas y normas inválidas. 2.5. Normas y principios. 3. Estructura. 3.1. Fundamentación de normas. 3.1.1. En el vértice del ordenamiento. 3.1.2. La identidad del ordenamiento. 3.2. Jerarquías de normas. 4. Complejidad. 5. Sincronía y diacronía. 6. El carácter mixto (estático-dinámico) de los ordenamientos jurídicos. 7. El ordenamiento como "sistema". 7.1. Coherencia. 7.2. Consistencia. 8. Ordenamientos centralizados y ordenamientos descentralizados. 9. Formación, contenido y extensión del ordenamiento. 9.1. El modo de formación. 9.2. El contenido. 9.3. La extensión. 10. Relaciones entre ordenamientos. 11. Los "problemas" del ordenamiento. 11.1. Lagunas. 11.2. Antinomias. 11.3. Lagunas, antinomias, interpretación.
\end{abstract}

ABSTRACT. In this paper the author deals with the following questions about legal systems: 1. Conceptions. 1.1. A legal system considered as a set of rules. 1.2. A legal system considered as a set of institutions. 2. Components. 2.1. Original norms and derived norms. 2.2. Formulated norms and implicit norms. 2.3. Primary norms and secondary norms. 2.4. Valid norms and invalid norms. 2.5. Norms and principles. 3. Structure. 3.1. Grounds for norms. 3.1.1. At the apex of the legal system. 3.1.2. The identity of the legal system. 3.2. Hierarchies of norms. 4. Complexity. 5. Synchrony and diachrony. 6. The mixed nature (staticdynamic) of legal systems. 7. The legal order as a "system". 7.1. Coherence. 7.2. Consistency. 8. Centralized legal systems and decentralized legal systems. 9. Formation, content and extent of the legal system. 9.1. How the legal system is formed. 9.2. The content. 9.3. The extent. 10. Relationships between legal systems. 11. The "problems" in the legal system. 11.1. Gaps. 11.2. Antinomies. 11.3. Gaps, antinomies, interpretation. 


\section{Concepciones}

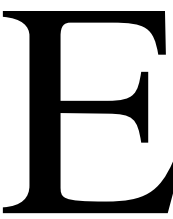

n la literatura se encuentran no menos de dos modos distintos de concebir los ordenamientos jurídicos.

Según el modo de ver estándar y generalmente compartido, un ordenamiento jurídico es un conjunto de normas.

Según un modo de ver sugerido por el institucionalismo italiano, un ordenamiento jurídico es más bien un complejo de instituciones.

Cada una de estas dos sucintas definiciones exige algunas palabras de aclaración.

\subsection{El ordenamiento como conjunto de normas}

En el uso común de los juristas y de las mismas fuentes del Derecho, el vocablo 'norma' es notoriamente ambiguo: a veces se usa para denotar los enunciados lingüísticos que se encuentran en el discurso de las fuentes; otras veces se usa para denotar el contenido de significado de tales enunciados; con frecuencia, ciertamente, se usa para denotar indistintamente una cosa y la otra ${ }^{1}$. Adoptando una convención lingüística ya ampliamente aceptada ${ }^{2}$, podemos llamar (no normas, sino) 'disposiciones' a los enunciados del discurso de las fuentes y reservar el nombre de 'normas' en sentido estricto a su contenido de sentido, tal y como resulta de la interpretación ${ }^{3}$.

A la luz de esta distinción, la primera concepción del ordenamiento (el ordenamiento como conjunto de normas) se duplica: en el sentido de que el ordenamiento puede concebirse alternativamente o como conjunto de disposiciones o como conjunto de normas propiamente dichas ${ }^{4}$.

(i) En el primer caso, un ordenamiento jurídico se presenta banalmente como un conjunto de textos normativos (la constitución, las leyes, etc.) ${ }^{5}$,

\footnotetext{
${ }^{1}$ Como si a cada enunciado correspondiera una, y solo una, norma, y a cada norma un, y sólo un, enunciado. Este uso indistinto del vocablo 'norma' presupone una concepción cognitiva de la interpretación, o sea, el modo de ver según el cual la interpretación es acto (no de voluntad, sino) de conocimiento (de manera que los enunciados interpretativos pueden ser verdaderos o falsos). Cf. R. Guastini, $L$ ' interpretazione dei documenti normativi, Milán, Giuffré 2004, cap. II.

${ }^{2}$ V. Crisafulli, “Disposizione (e norma)”, en Enciclopedia del diritto, XIII, Milán, Giuffré, 1964. Cfr. también R. Guastini, "Disposizione vs. norma”, en Giurisprudenza costituzionale, 1989, p. 3 y ss.

${ }^{3}$ R. Guastini, L’ interpretazione dei documenti normativi, cit., cap. VII.

${ }^{4}$ R. Guastini, “Ordinamento giuridico”, en Digesto delle discipline pubblicistiche, X, Turín, UTET, 1995.

${ }^{5}$ Así, por ejemplo, R. Hernández Marín, Teoría general del derecho y de la ciencia jurídica, Barcelona, PPU, 1989, especialmente cap. 2.
} 
pero su contenido normativo -qué se prescribe, a quién y en qué circunstancia- queda totalmente indeterminado.

(ii) En el segundo caso, un ordenamiento jurídico se presenta como un conjunto de significados, de contenidos normativos. Solo que tales significados son variables dependientes de la interpretación (ninguna disposición tiene un significado determinado si no es después de la interpretación ${ }^{6}$ ). De manera que, por una parte, el contenido normativo del ordenamiento resulta un tanto inaprensible, desde el momento en que toda disposición es susceptible de interpretaciones: (a) de un lado, sincrónicamente distintas y en conflicto; (b) de otro lado, diacrónicamente mutables ${ }^{7}$. Por otra parte, el ordenamiento está destinado a cambiar cuando cambia la interpretación dominante o consolidada sin que cambien las llamadas fuentes del Derecho.

En lo que sigue trataremos del ordenamiento como un conjunto de normas entendidas en sentido estricto, sin ulteriormente problematizar la distinción entre disposiciones y normas.

\subsection{El ordenamiento como complejo de instituciones}

A comienzos del siglo pasado, Santi Romano sugirió la idea de que un ordenamiento jurídico es un complejo (no de normas, sino) de "instituciones": en este sentido, por ejemplo, constituye (parte de) un ordenamiento no el conjunto de las normas constitucionales, sino el conjunto de los órganos constitucionales $^{8}$. De manera que, por ejemplo, se tiene una laguna en el ordenamiento (no cuando falta una norma que regula un cierto supuesto de hecho, sino) cuando de hecho desaparece una determinada institución (pongamos: la monarquía, por extinción de la casa reinante; la cámara electiva, por la abstención persistente del voto del cuerpo electoral, etc.). A este respecto, por lo demás, no será inútil hacer dos observaciones.

En primer lugar, 'institución' es un concepto exquisitamente normativo; y ello bajo un doble perfil ${ }^{9}$. Por un lado, ningún individuo o grupo de individuos puede ser identificado como institución (o como órgano) si no es a la

\footnotetext{
${ }^{6}$ G. Tarello, L’ interpretazione della legge, Milán, Giuffré, 1980.

${ }^{7}$ Conviene subrayar que la concepción que se examina no incluye en la noción de ordenamiento ni las decisiones jurisdiccionales y administrativas, ni la dogmática.

${ }^{8}$ No se alude aquí a la obra más conocida de Santi Romano (L'ordinamento giuridico, II ed., Florencia, Sansoni, 1946, donde el Derecho en su conjunto es representado como "institución”), sino al ensayo “Osservazioni sulla completezza dell’ ordinamento statale”, 1925, ahora en Id., Lo Stato moderno e la sua crisi. Saggi di diritto costituzionale, Milán, Giuffré, 1969.

${ }^{9}$ Una reescritura normativista de la concepción institucionalista del Derecho se lee en N. Bobbio, Teoria generale del diritto, Torino, Giappichelli, 1993, 12 ss. Cfr. también A.G. Conte, Filosofía dell'ordinamento normativo, Turín, Giappichelli, 1997, 352 ss.
} 
luz de un conjunto de normas (constitutivas) que le atribuyan tal valor ${ }^{10}$. Por otro lado, una institución parece enteramente reducible a (no parece tener una existencia independiente de) el conjunto de las normas que, imponiendo obligaciones y confiriendo poderes y derechos a ciertos sujetos, regulan su funcionamiento ${ }^{11}$.

En segundo lugar, la desaparición por la vía de hecho de una institución, como la casa reinante en un ordenamiento monárquico, no daría lugar en absoluto a una laguna ("institucional”) -si no quizás a una laguna del todo efímera- donde existiera una norma que regulase la circunstancia en cuestión (en el ejemplo, el supuesto de hecho: extinción de la casa reinante).

Como quiera que sea, esta concepción, salvo quizás algún homenaje completamente extrínseco (verbal) ${ }^{12}$, nunca ha alcanzado un gran éxito: los juristas han seguido pensando que un ordenamiento es un conjunto de normas y tratándolo así. En lo que sigue adoptaremos la concepción normativa, que es la ampliamente dominante.

No es ocioso recordar que, evidentemente, la locución 'ordenamiento jurídico’ asume el significado común de conjunto normativo también en el lenguaje de las fuentes vigentes del Derecho (la alusión lo es a las disposiciones siguientes: art. 8, 2 const. italiana; art. 10, 1, const. italiana; art. 12, 2, disposiciones preliminares del cod. civil italiano; art. 3 Estatuto de Cerdeña; art. 2 Estatuto Valle de Aosta; art. 4 Estatuto Friuli-Venezia Giulia; art. 4, Estatuto Trentino-Alto Adigio).

\section{Componentes}

Los componentes de un ordenamiento jurídico entendido como ordenamiento normativo, son, va de suyo, normas. Sin embargo, las normas que componen un ordenamiento conviene distinguirlas desde, al menos, cuatro perspectivas.

\subsection{Normas originarias y normas derivadas}

En primer lugar, conviene distinguir las normas originarias de las derivadas $^{13}$.

${ }^{10}$ J.R. Searle, Speech Acts. An Essay in the Philosophy of Language, Cambridge, Cambridge U.P., 1969. Cfr. también M. Atienza, J. Ruiz Manero, Las piezas del Derecho. Teoría de los enunciados jurídicos, Barcelona, Ariel, 1996, especialmente cap. 2.

${ }^{11} \mathrm{~N}$. Bobbio, Teoria generale del diritto, cit., $13 \mathrm{~s}$.

12 Por parte, por otro lado, sólo de la doctrina italiana

${ }^{13}$ Cfr. G.H. von Wright, Norm and Action. A Logical Enquiry, Routledge \& Kegan Paul, Londres, 1963, 199; R. Caracciolo, El sistema jurídico. Problemas actuales, Madrid, Centro de Estudios Constitucionales, 1988, 31 ss.; E. Bulygin, Norme, validità, sistemi normativi, Giappi- 
(i) Son originarias -independientes, "soberanas"- las normas cuya pertenencia al ordenamiento no depende de la (previa) existencia de otras normas. Son tales las normas constitucionales o, si se quiere, las normas de la "primera" constitución ${ }^{14}$ (en el caso de una secuencia de constituciones, cada una de las cuales está jurídicamente fundamentada ${ }^{15}$ en la precedente). Las normas constitucionales, en efecto, son -por definición- fruto del ejercicio de poder constituyente, o sea, de un poder extra ordinem, no conferido ni regulado por ninguna norma preexistente (de otra forma, se trataría, de un poder no constituyente, sino constituido).

(ii) Son derivadas -dependientes- todas las normas restantes: es decir, todas aquellas cuya existencia reposa -dinámica o estáticamente ${ }^{16}$ en la previa existencia de otras normas, o porque (a) han sido dictadas por un sujeto investido de autoridad normativa por una norma preexistente ${ }^{17}$, o porque (b) derivan ${ }^{18}$ lógicamente (o pseudo-lógicamente) de normas preexistentes $^{19}$.

\subsection{Normas formuladas y normas implícitas}

En segundo lugar, conviene distinguir entre normas expresamente formuladas ("dictadas" o "promulgadas" en sentido genérico y atécnico) y normas implícitas, no formuladas.

(1) Son formuladas las normas que, precisamente, encuentran una expresa enunciación en alguna disposición normativa (o en un fragmento de disposición normativa).

(2) Son implícitas, por el contrario, las normas extraídas de las normas formuladas (o de una combinación de normas formuladas, o de una combinación de fragmentos de normas formuladas) mediante procedimientos argumentativos lógicos (es decir, deductivos) o pseudo-lógicos (por ejemplo, por vía de analogía).

chelli, Turín, 1995, cap. XIII, Id., “El problema de la validez en Kelsen”, en R. Vázquez (ed.), Filosofía jurídica. Ensayos en homenaje a Ulises Schmill, Porrúa-ITAM, México, 2005.

${ }^{14}$ Una "primera constitución" es una constitución “originaria”, o sea, no derivada de (no jurídicamente fundamentada en) una constitución precedente. Véase H. Kelsen, Dottrina pura del diritto (1960), Turín, Einaudi, 1966, 225.

${ }^{15}$ Infra § 3.1., sub (i)

${ }^{16}$ Infra, § 3.1 .

${ }^{17}$ En este sentido, por ejemplo, son normas dependientes todas las normas de las leyes, ya que su existencia reposa sobre las normas constitucionales que atribuyen competencia legislativa.

${ }^{18}$ De las maneras que veremos en seguida, sub $\S 2.2$.

${ }^{19}$ En este sentido, son normas dependientes todas las normas implícitas, sobre las cuales infra §. 2.2. 
Toda norma implícita es fruto (no de promulgación o dictado, sino) de un razonamiento de los intérpretes. Se pueden, sin embargo, distinguir al menos cuatro tipos de razonamiento cuya conclusión es una norma implícita. O, dicho de otra manera, se pueden distinguir cuatro tipos de normas implícitas, a cada uno de los cuales corresponde un tipo distinto de razonamiento ${ }^{20}$.

(a) En primer lugar, hay normas implícitas que se extraen a partir de normas expresas mediante razonamientos lógicamente válidos (o sea, deductivos) $)^{21}$, en los que no figuran premisas que no sean normas expresas ${ }^{22}$.

(b)En segundo lugar, hay normas implícitas que se extraen de normas expresas mediante razonamientos lógicamente válidos, en los que figuran premisas que no son precisamente normas expresas, sino que son enunciados interpretativos: por ejemplo, definiciones de términos usados en la formulación de normas expresas ${ }^{23}$.

(c) En tercer lugar, existen normas implícitas que son fruto de razonamientos (a veces válidos, a veces inválidos) entre cuyas premisas figuran enunciados que no son precisamente normas expresas, sino que son más bien tesis dogmáticas construidas previamente e independientemente de la interpretación de cualquier específico enunciado normativo ${ }^{24}$.

${ }^{20}$ R. Guastini, L'interpretazione dei documenti normativi, cit., 104 ss.

${ }^{21}$ Un razonamiento tiene estructura deductiva cuando la conclusión está lógicamente implícita en las premisas. Los razonamientos deductivos son “cogentes” o “constringentes”, en el sentido de que, si se aceptan las premisas, no se puede (sin contradecirse) rechazar la conclusión: las premisas, digámoslo así, “garantizan” la conclusión.

22 Por ejemplo, dada una norma expresa N1 que establece "los mayores de edad tienen derecho de voto", y otra norma expresa N2 que establece "Los que hayan cumplido dieciocho años son mayores de edad”, se puede deductivamente inferir la norma implícita N3: "Los que hayan cumplido 18 años tienen derecho de voto”.

${ }^{23}$ Por ejemplo, una norma expresa establece que "Contra los actos de la Administración pública se admite siempre la tutela jurisdiccional de los derechos y de los intereses legítimos ante los órganos de jurisdicción ordinaria o administrativa” (art. 113, 1, const. italiana). Ahora bien, quien, a partir de esta norma, quisiera extraer la conclusión de que la tutela jurisdiccional se admite no sólo contra las actuaciones (singulares y concretas) de la administración pública, sino también contra los reglamentos, debería añadir la premisa de que por 'actos administrativos' debe entenderse cualquier acto (también normativo) proveniente de la administración pública. Semejante premisa constituye obviamente una interpretación del sintagma 'actos administrativos': es, pues, un enunciado interpretativo. Quien, por el contrario, a partir de esta misma norma, quisiera extraer la conclusión de que se puede impugnar ante alguna jurisdicción ordinaria o administrativa no sólo (literalmente) los actos provenientes de la administración pública, sino también las llamadas leyes-medida, debería añadir la premisa de que por 'actos administrativos' debe entenderse no (sólo) actos "subjetivamente” administrativos, sino (también) actos "sustancialmente" administrativos (esto es, que tienen contenido singular y concreto, si bien no han sido adoptados por la administración pública, sino por el legislador). Esta ultima premisa, de nuevo, sería fruto de la interpretación del sintagma 'actos administrativos'.

${ }^{24}$ Por ejemplo, la constitución [italiana] exige que el Gobierno tenga la confianza de las Cámaras (art. 94, 1, const.); la constitución, por lo tanto, ha instaurado un gobierno parlamentario; en el 
(d) En cuarto lugar, existen normas implícitas que se extraen, más o menos, persuasivamente a partir de normas expresas según esquemas de razonamiento no deductivos, lógicamente inválidos (por ejemplo, un entimema, una conjetura sobre la ratio legis, el argumento analógico, el argumento a contrario, etc. $)^{25}$.

\subsection{Normas primarias y normas secundarias}

En tercer lugar, conviene distinguir entre normas primarias y normas secundarias ${ }^{26}$.

(i) Se suele llamar primarias a las normas comunes de conducta, o sea, las normas que atribuyen o imponen situaciones jurídicas subjetivas (derechos, obligaciones, etc.) a los ciudadanos comunes ${ }^{27}$.

(ii) Se llaman, por el contrario, secundarias las normas -más precisamente: las meta-normas ${ }^{28}$-sobre la producción y la aplicación del Derecho, o sea, aquellas que confieren poderes ("legislativos" en sentido material, ejecutivos, jurisdiccionales) y regulan su ejercicio ${ }^{29}$.

gobierno parlamentario el Jefe del Estado no tienen poderes de dirección política, sino sólo funciones de garantía constitucional; por lo tanto, el Jefe del Estado no puede rechazar el dictado de los actos deliberados por el Gobierno salvo cuando se trate de actos notoriamente inconstitucionales.

${ }^{25}$ Un ejemplo entre mil: "La salud es un derecho fundamental del individuo" (se trata, en hipótesis, de una norma expresa: art. 32, 1, const. it.); "El daño a la salud constituye una violación de un derecho fundamental”; "La violación de un derecho fundamental constituye un daño injusto (en el sentido del art. 2043 cod. civ. it.)”, "Por lo tanto, el daño a la salud debe ser resarcido”. O también: una cierta disposición legal impone una obligación a los “ciudadanos”; argumentando a contrario (en una de las posibles variantes de tal argumento), se puede sostener que la disposición en cuestión -puesto que impone una obligación a los ciudadanos, sin mencionar sujetos distintos de los ciudadanos- excluye positivamente a los extranjeros y a los apátridas de la sujeción a tal obligación (es decir, contiene también la norma implícita según la cual los extranjeros y los apátridas no están sujetos a la obligación en cuestión).

${ }^{26}$ H.L.A. Hart, The concept of Law, Oxford, Clarendon, 1961; N. Bobbio, Studi per una teoría generale del diritto, Turín, Giappichelli, 1970, 175 ss.; N. Bobbio, Contributi ad un dizionario giuridico, Turín, Giappichelli, 1994, 177 ss, 233 ss.

${ }^{27}$ En los ordenamientos de tipo liberal, el conjunto de las normas primarias está cerrado por el principio de libertad: "Todo lo que no está expresamente prohibido está (implícitamente) permitido”. Cfr. D. Donati, Il problema delle lacune dell’ ordinamento giuridico, Milán, 1910 (ahora en Id., Scriti di diritto publico, I, Padua, 1966).

${ }^{28}$ Se llama metanorma a toda norma que tenga como objeto no la conducta, sino: (a) actos normativos (ejemplo: "La función legislativa se ejerce colectivamente por las dos Cámaras”, art. 70 cons. it.); (b) otras normas (ejemplo: el principio de retroactividad); o (c) otras disposiciones (ejemplo: "Se deroga el art. x de la ley y"). Sobre ello: T. Mazzarese, "Metanorme. Rilievi su un concetto scomodo della teoria del diritto", en P. Comanducci, R. Guastini (eds), Struttura e dinamica dei sistemi giuridici, Giappichelli, Turín, 1996.

${ }^{29}$ En los ordenamientos de tipo liberal, el conjunto de las normas secundarias está cerrado por el principio de legalidad: “Todo lo que no está expresamente permitido está (implícitamente) prohibido”. Cfr. G. Zagrebelsky, Il diritto mite. Legge, diritti, giustizia, Turín, 1992, 31. 
Dentro de las normas secundarias ocupan un lugar especial las llamadas normas "sobre la producción jurídica", o normas sobre las fuentes: es decir, las que confieren, y regulan el ejercicio de, competencias normativas ${ }^{30}$.

\subsection{Normas válidas y normas inválidas.}

En cuarto lugar, conviene distinguir entre normas válidas y normas inválidas. Es realmente una ingenuidad -bastante difundida en la teoría del Derecho ${ }^{31}$ - pensar que sólo las normas válidas pertenecen al ordenamiento ${ }^{32}$.

Se llama válida toda norma que sea formalmente conforme y materialmente no incompatible con las normas y metanormas que son, respecto de ella, formal y materialmente superiores ${ }^{33}$.

Pero la validez no es condición necesaria de "existencia jurídica" (esto es, de pertenencia al ordenamiento) de una norma. De hecho, en todo ordenamiento existen fatalmente también normas inválidas: leyes inconstitucionales, reglamentos contra legem, etc. Normas que pueden también ser durante un largo tiempo observadas y aplicadas antes de que su invalidez sea (constitutivamente) reconocida por el órgano competente para ello ${ }^{34}$.

Se podría añadir: en todo ordenamiento existen también normas ni válidas, ni inválidas. Aludo evidentemente a las normas supremas, originarias, o independientes ${ }^{35}$, o sea, a las normas constitucionales. En ausencia de

${ }^{30}$ Cfr. R. Guastini, Teoria e dogmatica delle fonti, Milán, Giuffrè, 1998, cap. IV.

${ }^{31}$ Donde es completamente común definir la validez como pertenencia al ordenamiento.

${ }^{32}$ L. Ferrajoli, Diritto e ragione. Teoria del garantismo penale, Bari-Roma, Laterza, 1989, esp. 909 y ss.; E. Bulygin, “El problema de la validez en Kelsen”, 5 s.

${ }^{33}$ Los conceptos que subyacen a esta definición se explican infra: aps. 3.1 y 3.2.

${ }^{34}$ A esta manera de ver las cosas, que distingue entre pertenencia ("existencia jurídica”) y validez, se le podría objetar aproximadamente así: las normas en cuestión (leyes inconstitucionales, etc.), al ser inválidas, no pertenecen de ningún modo al ordenamiento; a pesar de ello son aplicables (hasta que no sean declaradas inválidas por el órgano competente); pero, justamente, eso no quiere decir que pertenezcan al ordenamiento, ya que una cosa es la validez o pertenencia, y otra cosa la aplicabilidad (véase, por ejemplo, el caso de las normas extranjeras, reclamadas por normas de Derecho internacional privado: normas aplicables, pero ciertamente no pertenecientes al ordenamiento). En suma: bien vistas las cosas, lo que tu llamas "existencia jurídica” no es para nada "pertenencia al ordenamiento"; es, banalmente, la aplicabilidad. Este tipo de ideas están en Bulygin, "El problema de la validez en Kelsen”, cit. Así, decía, se podría objetar. Pero sería equivocado. Lo que llamo "existencia jurídica” es algo distinto no sólo de la validez, sino también de la aplicabilidad. Tomemos el caso de una ley inconstitucional en periodo de vacatio: semejante ley es (en hipótesis) inválida; no es aplicable (mientras dure la vacatio); pero sin embargo pertenece ya al ordenamiento, al haber sido promulgada y publicada. Es precisamente esta "pertenencia” lo que la distingue de un proyecto de ley a la espera de aprobación, igualmente no aplicable y (por hipótesis) igualmente inconstitucional.

${ }^{35}$ Supra, § 2.1. 
normas sobre la instauración (a no confundir con la revisión ${ }^{36}$ ) constitucional y de normas materialmente superiores a la constitución, no tiene sentido predicar ni la validez ni la invalidez de la constitución ${ }^{37}$.

\subsection{Normas y principios}

Hoy es una opinión generalmente compartida que todo ordenamiento está compuesto no sólo por "normas", sino también por "principios” (adjetivados bien como "generales”, o bien como "fundamentales”) ${ }^{38}$. Pero la distinción entre normas y principios es un tanto escurridiza, bajo al menos dos aspectos ${ }^{39}$.

${ }^{36}$ Infra, § 3.1.2.

${ }^{37}$ R. Guastini, "La validité de la constitution du point de vu du positivisme juridique”, en M. Troper, L. Jaume (eds.), 1789 et l'invention de la constitution, Bruselas-París, BruylantL.G.L.J., 1994, 216 ss.

${ }^{38}$ La literatura al respecto es muy vasta. Me limito a mencionar unos pocos textos esenciales: R. Dworkin, Taking Rights Seriously, II ed., Londres, Duckworth, 1978, espec. cap. 2; G. R. Carrió, "Principi di diritto e positivismo giuridico” (1970), ahora en R. Guastini (ed.), Problemi di teoria del diritto, Bolonia, Il Mulino, 1980; R. Alexy, Teoría de los derechos fundamentales (1986), Madrid, Centro de Estudios Constitucionales, 1993, espec. cap. 3; L. Prieto Sanchís, Sobre principios y normas. Problemas del razonamiento jurídico, Madrid, Centro de Estudios Constitucionales, 1992; M. Atienza, J. Ruiz Manero, Las piezas del Derecho. Teoría de los enunciados jurídicos, Barcelona, Ariel, 1996, espec. cap. 1.

${ }^{39}$ La distinción, debe subrayarse, tiene relevancia no sólo teórica, sino también dogmática, a causa de numerosas disposiciones de Derecho positivo vigente que, precisamente, hacen referencia también ellas a los principios en cuanto algo distinto a las otras normas. Los ejemplos más macroscópicos son probablemente los siguientes.

El art. 117, 3 de la Cons. it. (tal y como fue reformulado por el art. 3 de la ley const. 3/2001) dispone entre otras cosas que "En las materias de legislación concurrente corresponde a las Regiones la potestad legislativa, salvo en lo que respecta a la determinación de los principios fundamentales, reservada a la legislación del Estado”; y, al hacer así, impone el distinguir, dentro de la regulación de cada "materia” confiada a la legislación concurrente, las normas que constituyen "principios fundamentales" de las restantes (El mismo art. 117, inciso 1, en la formulación originaria, autorizaba a las Regiones con estatuto ordinario a dictar "normas legislativas en los límites de los principios fundamentales establecidos por las leyes del Estado”; y, al hacer así, imponía distinguir entre "normas" sin ulteriores especificaciones y "principios fundamentales”).

El art. 9, 1, ley 62/1953, tal como fue modificada por el art. 17, inciso último, ley 281/1970, dispone a su vez que "el dictado de normas legislativas por parte de las regiones [...] se desarrolla en los límites de los principios fundamentales como resultan de las leyes que expresamente los establecen para cada materia o como se desprenden de las leyes vigentes”. Esta disposición (¿todavía vigente después de la revisión constitucional de 2001?) sugiere distinguir entre principios explícitos (los que resultan de las "leyes que expresamente los establecen”) y principios implícitos (los que, justamente, no están expresamente establecidos por las leyes, pero que, sin embargo, "se desprenden" de leyes).

El art. 12, 2. disp. prel. cód. civ. it por su lado -al disponer que "si una controversia no puede decidirse con una disposición precisa [...] se decide según los principios generales del 
Por un lado, no está claro en qué sentido puede decirse que los principios jurídicos son algo distinto a las normas. Parece obvio, por el contrario, que son no ya otras normas, sino, a lo más, un tipo específico de normas jurídicas.

Por otro lado, no está claro cuáles son los rasgos distintivos de los principios con respecto al resto de las normas, ya que el concepto de principio no es en absoluto unívoco.

En la literatura se encuentran no menos de tres conceptos de principio. Naturalmente, a una pluralidad de conceptos corresponde una pluralidad de clases. Pero, por otra parte, hay principios que caen simultáneamente en más de una clase.

(i) Según una cierta perspectiva, los principios son normas "con el supuesto de hecho abierto" y/o "normas derrotables “

El supuesto de hecho (el antecedente) de una norma está "cerrado", cuando la norma enumera exhaustivamente bien sea los hechos en presencia de los cuales se produce la consecuencia jurídica que ella misma dispone, $o$ bien las eventuales excepciones, o sea, los hechos en presencia de los cuales la consecuencia jurídica no se produce. El supuesto de hecho (el antecedente) de una norma es "abierto", cuando la norma no enumera exhaustivamente los hechos en presencia de los cuales se produce la correspondiente consecuencia, o bien no enumera exhaustivamente las excepciones en presencia de las cuales la consecuencia no se produce.

Una norma es "no derrotable" cuando no admite excepciones o, mejor dicho, no admite otras excepciones si no las expresamente establecidas por la propia norma o por otras normas del ordenamiento. Una norma es "derrotable" cuando admite excepciones implícitas, no establecidas por la norma en cuestión, ni por ninguna otra norma del ordenamiento, y por tanto indeterminadas ${ }^{40}$.

ordenamiento jurídico del Estado- impone distinguir entre “disposiciones precisas” y "principios generales".

De "principios e intereses generales los cuales informan la legislación del Estado" habla también el art. 17 del Estatuto de la Región siciliana (Real decreto legislativo 455/1946, convertido en ley const. 2/1948). Los "principios del ordenamiento jurídico del Estado" se mencionan en el art. 3 del Estatuto especial para Cerdeña (ley const. 3/1948), en el art. 2 del Estatuto especial para el Valle de Aosta (ley const. 4/1948), así como en el art. 4 del Texto único de las leyes const. relativas al Estatuto especial para el Trentino-Alto Adigio (D.P.R. 670/1972), el último de los cuales, en el art. 5, contrapone los "principios establecidos por las leyes del Estado" a las "normas legislativas" regionales. Poniendo, pues, uno al lado del otro, estos diversos textos normativos, parece inevitable distinguir ulteriormente (si no también entre "normas" y “disposiciones precisas", por lo menos) entre "principios fundamentales" y "principios generales".

${ }^{40}$ Esta (doble) distinción puede ilustrarse con un simple ejemplo. El art. 3, 1, cons. it. -“Todos los ciudadanos [...] son iguales ante la ley, sin distinción de sexo, de raza, de lengua, 
(ii) Según una distinta perspectiva, los principios son normas "genéricas"41, las cuales: por un lado, (a) exigen el dictado de otras normas que les sirvan de realización o les den concreción; pero, por otro lado, (b) pueden ser realizadas o concretadas de muchas maneras distintas y alternativas ${ }^{42}$.

de religión, de opiniones políticas, de condiciones personales y sociales”- admite dos distintas interpretaciones: puede ser entendido alternativamente como norma específica, con un supuesto de hecho cerrado, o como norma derrotable, con supuesto de hecho abierto, o sea, como principio.

(a) En la primera interpretación, la disposición expresa grosso modo la norma siguiente: si una ley distingue entre ciudadanos según el sexo, la raza, etc. (supuesto de hecho), entonces ella es constitucionalmente ilegítima (consecuencia jurídica). Por un lado, una tal norma no admite excepciones: está excluido que una ley, que discrimine según el sexo, la raza, etc., pueda nunca ser conforme con la constitución. Por otro lado, semejante norma tiene un supuesto de hecho cerrado: está excluido que (en el sentido de esta norma) una ley pueda ser constitucionalmente ilegítima si se diera el caso de que discriminara por razones distintas del sexo, la raza, etc.

(b) En la segunda interpretación, la misma disposición expresa un principio genérico de igualdad, que se suele formular así: los casos iguales deben ser tratados de manera igual, los casos desiguales deben ser tratados de manera desigual. Por un lado, este principio admite excepciones: no está en absoluto excluido que una ley pueda ser constitucionalmente legítima aun discriminando a los ciudadanos, por ejemplo, según el sexo (a pesar del mismo sexo, las situaciones pueden muy bien ser "objetivamente" desiguales y, cabalmente, el legislador debe tratar de manera desigual situaciones objetivamente desiguales). Por otro lado, este principio tiene un supuesto de hecho abierto: no está en absoluto excluido que una ley pueda ser constitucionalmente ilegítima porque discrimina según criterios distintos del sexo, de la raza, etc. (por ejemplo, según la edad: a pesar de la distinta edad, las situaciones pueden muy bien ser “objetivamente” iguales y, cabalmente, el legislador debe tratar de manera igual situaciones objetivamente iguales). Obsérvese, sin embargo: la derrotabilidad no es una característica exclusiva de los principios. En verdad, cualquier disposición puede convertirse en derrotable (o con supuesto de hecho abierto) mediante una oportuna técnica interpretativa (sin, por ello, ser considerada un principio). La técnica en cuestión es la de la disociación. Cfr. R. Guastini, L'interpretazione dei documenti normativi, cit., cap. IX.

${ }^{41}$ A principios de este tipo nos referimos cuando se habla de sentencias constitucionales “aditivas de principio”. Cfr. G. Parodi, La sentenza additiva a dispositivo generico, Turín, Giappichelli, 1996.

${ }^{42}$ Nuevamente, el punto puede aclararse con un simple ejemplo. El art. 139 cons. it. dispone que la "forma republicana" del estado no puede ser objeto de revisión constitucional. Ahora bien, la forma republicana del estado se caracteriza por oposición paradigmática a la forma monárquica. La distinción está en la distinta actitud hacia la figura del jefe del Estado. Más precisamente, en el lenguaje político común, el vocablo 'república’ denota esencialmente aquel tipo de organización política en la cual: a) el jefe del Estado es órgano electivo; y (b) el mandato del jefe del Estado está limitado en el tiempo. Ahora bien, la constitución (italiana) vigente en el art. 83 dispone que el Presidente de la República sea elegido por las Cámaras en sesión común y, en el art. 85 inciso 1, fija la duración del mandato presidencial en siete años. Pero la Constitución bien podría concretar de manera distinta los dos principios en cuestión: el carácter electivo del jefe del Estado y el carácter temporal de su mandato. De manera que sería equivocado concluir que, en virtud del art. 139, esté del todo excluida la revisión de estas dos disposiciones. Bien vistas las cosas, el art. 139 cons. it. no prohibe cualquier revisión de los arts. 83 y 85, inciso 1, que expresan normas específicas. No prohibe, por ejemplo, modificar la duración del mandato presidencial, mientras se conserve su carácter temporal; no prohibe 
(iii) Según una perspectiva todavía distinta, los principios se distinguen de las normas específicas no ya (o no tanto) por su contenido y su estructura, sino más bien por la "posición" que ocupan en el ordenamiento jurídico o en alguno de sus sectores particulares (el Derecho constitucional, el Derecho civil, el Derecho procesal, el Derecho administrativo, etc.). Los principios son normas "fundamentales". Lo son en un doble sentido.

(a) En primer lugar, los principios son normas "fundamentales" en el sentido de que sirven de fundamento y/o justificación a otras normas (en general, cada principio constituye el fundamento de una multiplicidad de otras normas). Todo conjunto de normas -unidas por un mismo objeto de regulación- presupone y sobreentiende valores, elecciones políticas caracterizadoras de ideas de justicia: por ejemplo, la división de poderes, la igualdad entre los ciudadanos, la paz entre las naciones, la llamada certeza del Derecho (o sea: previsibilidad de las consecuencias jurídicas de las acciones propias y, al mismo tiempo, estabilidad de las relaciones establecidas), la libertad contractual (o autonomía privada), la tutela de quien actúa de buena fe, y así sucesivamente. Pues bien, dado un conjunto cualquiera de normas (que puede incluso coincidir con todo el ordenamiento), se consideran principios aquellas normas que incorporan tales valores, sentimientos de justicia, decisiones políticas ${ }^{43}$

cambiar el modo de elección del Jefe del Estado, mientras se conserve su carácter electivo. Lo que el art. 139 const. prohibe es alterar o suprimir los dos principios que -si bien no expresamente formulados- subyacen a las dos normas en cuestión: o sea, el principio del carácter electivo del jefe del Estado y el principio del carácter temporal de su mandato. Sin embargo, cabalmente, estos dos principios pueden ser concretados de maneras distintas: el Presidente de la República podría, por ejemplo, ser elegido directamente por el pueblo, en lugar de por las Cámaras reunidas, sin que el principio subycente resultara violado; su mandato podría prolongarse, pongamos, de siete años a diez, como también reducirse de siete años a cinco, sin con ello violar el principio subyacente.

Nótese que pertenecen a la clase de las normas “genéricas”, en el sentido que se ha tratado de aclarar, también las normas "teleológicas”: es decir, aquellas normas que no prescriben una precisa línea de comportamiento, sino que expresan solemnemente un valor, del que recomiendan su realización, o bien indican un fin a perseguir. Son ejemplos paradigmático de ello las numerosas normas "programáticas”, de las que está llena la constitución: art. 3, 2; art. 4, 1; art. 5; art. 6; art. 31; art. 32, 1; y así sucesivamente. También las normas teleológicas pueden ser realizadas o concretadas de muchas maneras distintas y alternativas: tantas cuantos sean los medios idóneos para perseguir el fin prescrito o para realizar el valor proclamado. Basta pensar, para poner algún ejemplo, en los mil modos posibles de "tutelar la salud” (art. 32, 1, cons. it.), o de "tutelar a las minorías lingüísticas” (art. 6 const. it.).

${ }^{43}$ Por ejemplo, el principio de tutela de la confianza fundamenta y justifica las disposiciones sobre el error como causa de anulación del contrato (art. 1428 cod. civ. it.), las disposiciones sobre los efectos de la simulación con respecto a terceros y a los acreedores (arts. 1415 y 1416 cod. civ. it.), las disposiciones que limitan la oponibilidad frente a terceros de la modificación o revocación del poder (art. 1396 cod. civ. it.), etc. 
(b) En segundo lugar, los principios son normas “fundamentales” en el sentido de que no requieren, o parecen no requerir, a su vez fundamento o justificación: puesto que -sin razón o con ella- son percibidos como obvios, autoevidentes, o como intrínsecamente justos. En suma, los principios son normas que, a los ojos de quien habla, revisten una especial "importancia”, o bien se presentan como normas "caracterizadoras" del ordenamiento o de una de sus partes, esenciales para su identidad o fisionomía ${ }^{44}$.

Obsérvese que las normas calificables como principios en virtud de su carácter "fundamental” no necesariamente tienen el supuesto de hecho abierto, son derrotables, o genéricas ${ }^{45}$.

\section{Estructura}

Un ordenamiento no es ya un conjunto de normas cualquiera, sino más bien un conjunto de normas "estructurado" ${ }^{4}$. La estructura, a la que se alude, consiste banalmente en esto: que las normas que componen un ordenamiento no están recíprocamente desconectadas y son entre sí independientes sino que, por el contrario, tienen relaciones las unas con las otras.

En este contexto, importa mencionar al menos dos relaciones relevantes: la (doble) relación de “fundamentar”, y la (múltiple) relación “jerárquica”.

\subsection{Fundamentación de normas}

Que una norma sirva de fundamento a otra norma puede decirse en dos sentidos distintos: el primero alude a la dinámica del ordenamiento, el segundo, a su estática.

(i) Diremos que una primera norma N1 sirve de fundamento "dinámico" a una segunda norma N2, cuando N2 ha sido creada por una autoridad normativa A instituida por N1. N1, en otros términos, es una norma de competencia, que confiere a una autoridad A el poder de crear N2, y A es la autoridad creadora de N2.

Es tesis generalmente aceptada -después de Kelsen- que los ordenamientos jurídicos están dotados de una estructura piramidal, en el sentido

\footnotetext{
${ }^{44}$ Piénsese, por ejemplo: en Derecho constitucional, en el principio de la soberanía popular o en el principio de la división de poderes; en Derecho civil, en el principio de la autonomía privada; en Derecho administrativo, en el principio del justo procedimiento; en Derecho penal, en el principio "nullum crimen, nulla poena, sine lege”; y así sucesivamente.

${ }^{45}$ Un solo ejemplo: se puede convenir en que la norma "lex posterior derogat priori” (art. 15 disp. prel. cod. civ. it.) constituye un principio, ya que desempeña en el ordenamiento un rol en algún sentido fundamental, pero es una norma con un supuesto de hecho cerrado y aparentemente no derrotable

${ }^{46}$ N. Bobbio, Teoria generale del diritto, cit., VIII; C. Leben, "De quelques doctrines de l' ordre juridique”, en Droits, 33, 2001, 20.
} 
siguiente $^{47}$. La norma (en hipótesis: ínfima) N4 encuentra su fundamento dinámico en la norma N3; esta, a su vez, recibe su fundamento dinámico de N2; N2 encuentra su fundamento dinámico en N1; esta a su vez recibe fundamento dinámico de N0 (en hipótesis: suprema) ${ }^{48}$.

Ahora bien, la norma N0, adviértase, carece, en hipótesis, de cualquier fundamento dinámico. Eso significa que N0 es una norma creada no ya por un poder jurídico -o sea, "constituido", conferido por una norma jurídica- sino por un poder "constituyente", un poder de hecho. La norma N0, no habiendo normas superiores a ella, es la norma suprema del ordenamiento: esto es, su "primera" constitución ${ }^{49}$. Todas las restantes normas del ordenamiento "dependen", en un sentido obvio, de NO. N0, a su vez, no depende de ninguna otra norma: ella es, por tanto, en este sentido, una norma "independiente" 50

(ii) Diremos que una primera norma N1 presta fundamento estático a una segunda norma $\mathrm{N} 2$, cuando $\mathrm{N} 2$ es derivable con instrumentos lógicos o pseudológicos de N1, en los modos que hemos visto ${ }^{51}$.

\subsubsection{En el vértice del ordenamiento}

Si desde el punto de vista dinámico el ordenamiento presenta, como se ha dicho, una estructura piramidal, es sensato preguntarse qué norma está en el vértice de la pirámide. La respuesta más conocida a esta pregunta es la de Kelsen: en el vértice del ordenamiento está una norma "fundamental", no "puesta", sino "presupuesta" (no válida, sino presupuesta como válida) ${ }^{52}$. Esta tesis no convence por la razón siguiente.

Kelsen no distingue entre validez y existencia de las normas: no admite que puedan existir normas que carezcan de cualquier fundamento de vali-

${ }^{47}$ Cfr. H. Kelsen, La dottrina pura del diritto, cit., 251 ss.

${ }^{48}$ La norma N0 es "superior" -estructuralmente superior (infra apdo. 3.2), en el sentido de que proporciona fundamento (dinámico), directo o indirecto- a todas las normas restantes. N1 es superior, en el mismo sentido, a N2, N3 y N4. N2 es superior a N3 y N4. N3, en fin, es superior a N4.

${ }^{49}$ Supra, § 2.1 .

${ }^{50}$ Obviamente, en el vértice de la pirámide no hay necesariamente una única norma suprema: puede haber múltiples, todas del mismo rango, en cuanto formuladas en un único documento normativo, producido por un poder de hecho. El documento que expresa el conjunto de las normas supremas de un ordenamiento es precisamente su (primera) constitución.

${ }^{51}$ Cfr. supra, § 2.2 .

52 La norma fundamental kelseniana no debe confundirse con la "regla de reconocimiento" teorizada por Hart, la cual (puede sostenerse) no es propiamente una norma, sino más bien un “criterio" (convencional) de reconocimiento de las normas válidas, o sea, una definición de 'norma válida'. Cfr. E. Bulygin, Norme, validità, sistemi normativi, Turín, Giappichelli, 1995, 19 ss. 
dez, y por lo tanto pretende encontrar un fundamento de validez a cualquier norma existente, incluida la (primera) constitución. De manera que, cuando se interroga sobre el fundamento de validez de la constitución, se ve inducido a presuponer una norma ulterior, "meta-constitucional”, ni válida ni inválida -llamada por el precisamente "fundamental”- que dé fundamento dinámico de validez a la propia constitución (confiriendo poder constituyente y/o mandando obedecer a la constitución).

Ahora bien, que el conjunto de las normas válidas deba necesariamente apoyarse sobre una norma ni válida ni inválida, y por tanto "suprema”, está fuera de discusión (por razones exquisitamente lógicas que aquí no viene al caso evocar ${ }^{53}$ ). Pero si no todas las normas pueden ser válidas, si tiene en cualquier caso que haber una norma ni válida ni inválida, ¿por qué no admitir que se trata de una norma no ya "presupuesta”, sino simplemente “puesta” (por un poder de hecho extra ordinem)? En otras palabras: ¿por qué no admitir que norma suprema es la misma (primera) constitución? ¿Por qué buscar un fundamento de validez a la constitución en una norma ulterior ni válida ni inválida, en lugar de admitir, más simplemente, que la (primera) constitución misma no es ni válida ni inválida ${ }^{54}$ Desde este punto de vista, la estipulación de la norma "fundamental” se revela del todo superflua: una inútil duplicación de la constitución ${ }^{55}$.

\subsubsection{La identidad del ordenamiento}

Se puede convenir que la identidad de todo ordenamiento (visto desde el punto de vista dinámico $)^{56}$ reposa en última instancia en la identidad de su norma suprema, esto es, en la identidad de su (primera) constitución. En el sentido de que todo ordenamiento, aunque cambien (incesantemente) las normas derivadas o dependientes que lo componen, conserva sin embargo su identidad mientras que no se cambien sus normas originarias o independientes, que sirven de fundamento dinámico de validez a todas las restantes ${ }^{57}$.

\footnotetext{
${ }^{53}$ Cfr., p. e. H.L.A. Hart, The Concept of Law, cit., 97 ss. Cfr. también V. Mathieu, "Sistemi logici e sistemi giuridici. Imposibilità di autofondazione formale”, en Id., Luci ed ombre del giusnaturalismo, Turín, 57 ss.

${ }^{54}$ Cfr. R. Guastini, “Sur la validité de la constitution du point de vue du positivisme juridique", cit.

${ }^{55} \mathrm{O}$, quizás, la ideología normativa de cuantos legitiman el sistema constitucional vigente: N. Bobbio, "Sul principio di legittimità" (1964), en N. Bobbio, Studi per una teoria generale del diritto, cit., 79 ss.

${ }^{56}$ Infra, § 5. Desde el punto de vista estático, un ordenamiento cambia, y en ese sentido cambia su identidad, cada vez que se introduzca en él una nueva norma o que una norma preexistente sea derogada (o anulada) o sustituida.

${ }^{57}$ E. Bulygin, Norme, validità, sistemi normativi, cit., 240.
} 
Mientras que un ordenamiento pierde su identidad originaria -su "continuidad”, es un ordenamiento distinto- cuando cambia su constitución.

Sin embargo, así como un hombre no pierde su identidad por el hecho de que le sea amputado un miembro y sustituido por un miembro artificial, parece obvio que un texto constitucional puede también ser repetidamente (y profundamente) enmendado sin perder por ello su identidad originaria. Se plantea entonces el problema de distinguir el cambio constitucional (la instauración de una "nueva" constitución) de la mera revisión constitucional (la enmienda de la constitución existente): de distinguir, en suma, el poder constituyente del poder (constituido) de revisión constitucional.

Ahora bien, del poder constituyente se encuentran, en la cultura jurídica contemporánea, dos concepciones distintas, a las que podemos llamar, respectivamente, "formalista" y "sustancialista".

(I) Según la concepción formalista, poder constituyente es aquel que-no siendo "constituido" (o sea, previsto y regulado por normas preexistentes)necesariamente se ejerce extra ordinem, o sea, en formas ilegales o en todo caso no-legales ${ }^{58}$. (Si se ejercitase en formas legales, o sea, de acuerdo con normas preconstituidas, entonces habría normas que lo conferirían y/o lo regularían. Pero si hubiera tales normas, entonces ese sería, por ello mismo, un poder no constituyente, sino constituido.)

(II) Según la concepción sustancialista, por el contrario, constituyente es aquel poder que -cualquiera que sean sus modos de ejercicio- expresa la "decisión política fundamental" "59: aquel poder, en suma, que elige los principios supremos y/o caracterizadores del ordenamiento o de la "forma del Estado".

A estas dos concepciones del poder constituyente le subyacen dos distintas concepciones de la constitución.

(i) La concepción formalista del poder constituyente tácitamente supone que la constitución es, banalmente, nada más que un conjunto de normas (como tal, definible extensionalmente, esto es, por simple enumeración de las normas que lo componen).

(ii) La concepción sustancialista del poder constituyente, a su vez, tácitamente supone que la constitución es, por el contrario, una totalidad coherente de principios y/o valores.

\footnotetext{
${ }^{58} \mathrm{Cfr}$. S. Romano, “L' instaurazione di fatto di un ordinamento costituzionale e la sua legittimazione” (1902), ahora en Id., Lo Stato moderno e la sua crisi. Saggi di diritto costituzionale, cit.; A. Pace, "L' instaurazione di una nuova costituzione. Profili di teoria costituzionale”, en Associazione italiana dei costituzionalisti, La nascita delle costituzioni europee del secondo dopoguerra, Pádua, CEDAM, 2000.

${ }^{59}$ C. Schmitt, Dottrina della costituzione (1928), Milán, Giuffré, 1984, 41, 109 ss.
} 
Estas dos concepciones de la constitución, a su vez, presuponen dos distintos criterios de identidad de la constitución.

(A) Según la concepción formalista, una constitución -un conjunto de normas- se comporta como cualquier otro conjunto: un conjunto pierde su identidad y se transmuta en un conjunto distinto, cada vez que se introduce un nuevo elemento o que un elemento preexistente es eliminado o sustituido. En otras palabras, la constitución pierde su identidad y pasa a ser una constitución distinta, cada vez que se produzca una (cualquiera) revisión constitucional. Por marginal que pueda ser el cambio, toda revisión constitucional produce una "nueva" constitución ${ }^{60}$. Lo que cuenta es distinguir entre revisiones "legales" (o sea, realizadas según las formas previstas por la propia constitución) y revisiones “ilegales” (o extra ordinem).

(B) Según la concepción sustancialista, por el contrario, una constitución -en cuanto totalidad coherente de principios- conserva su identidad mientras que, aunque modificada en una o más de sus normas, no sean alterados los principios supremos que la constituyen. Y por otra parte la constitución pierde su identidad cuando incluso uno solo de los principios fundamentales es alterado o suprimido. En suma, aquí importan no tanto las formas (legales o ilegales) de la revisión, cuanto su objeto.

Ahora bien, como se ha dicho, la revisión constitucional supone la identidad del texto constitucional al que se refiere, en el sentido de que parece natural usar el vocablo 'revisión' para denotar la modificación de un texto constitucional que conserve, sin embargo, su identidad. Se sigue de ello que las dos concepciones suponen dos modos divergentes de concebir la revisión constitucional y sus límites "naturales".

(a) Desde un punto de vista sustancialista, el poder de revisión constitucional no puede extenderse hasta afectar a los principios constitucionales supremos (puede sólo corregir marginalmente las restantes normas del texto constitucional): si actuara así, necesariamente se transmutaría en poder constituyente ${ }^{61}$. Alterar los principios supremos, en efecto, constituye no ya mera revisión de la constitución existente, sino genuina instauración de un nuevo ordenamiento constitucional. Una consecuencia relevante de este modo de ver es que no hay modos legales de cambiar la constitución (entendida, precisamente, como el conjunto de principios supremos): la constitución solo puede ser cambiada en formas ilegales, revolucionarias.

\footnotetext{
${ }^{60}$ E. Bulygin, Norme, validità, sistemi normativi, cit., 76 ss.

${ }^{61}$ Por ejemplo, en nuestro ordenamiento, en relación al art. 139 cons. it., se pueden perfectamente cambiar, mediante revisión constitucional, las modalidades de elección del Jefe del Estado, pero no el principio del carácter electivo del Jefe del Estado.
} 
(b) Desde un punto de vista formalista, por el contrario, el poder de revisión constitucional se distingue del constituyente solo por el hecho de ejercitarse en los modos previstos y regulados por la propia constitución. Por lo tanto, el cambio constitucional, cuando sea realizado en las formas previstas por la propia constitución, se queda en mera revisión -no se transmuta en instauración de un nuevo ordenamiento constitucional- cualquiera que sea su objeto: por mucho que la revisión pueda incidir a fondo sobre los principios supremos ${ }^{62}$. Consecuencia relevante de este modo de ver es que la constitución puede ser cambiada incluso profundamente en formas legales, sin que sean precisas revoluciones, golpes de Estado o guerras civiles.

\subsection{Jerarquías de normas}

Es pacífico que todo ordenamiento tiene una estructura jerárquica. ¿Pero de qué tipo de jerarquía exactamente estamos hablando?

Según Kelsen ${ }^{63}$, hay sólo un tipo de jerarquía: la que tiene lugar entre las normas sobre la producción jurídica y las normas producidas de acuerdo con ellas. En este sentido, por ejemplo, las normas constitucionales sobre la legislación están supraordenadas a la legislación misma incluso (nótese bien) cuando la constitución es flexible.

Según Merkl ${ }^{64}$, sin embargo, hay un segundo tipo de jerarquía (junto a la precedente): la relación que tiene lugar entre dos normas cuando una de ellas no puede válidamente ser contradicha o derogada por la otra. Obsérvese que, por lo que se refiere a las relaciones entre constitución y legislación, tal relación tiene lugar sólo si la constitución es rígida.

Por otro lado, la relación entre normas sobre la producción jurídica y normas producidas de acuerdo con ellas es con frecuencia vista como una relación lógica: el tipo de relación que existe entre dos niveles de lenguaje (un meta-lenguaje y su lenguaje-objeto) ${ }^{65}$. Este modo de ver, sin embargo, confunde esta relación con una relación completamente distinta: la que existe entre dos normas cuando la una se refiere metalingüísticamente a la otra, "habla" de la otra (por ejemplo, la relación entre una norma de derogación expresa y la norma por ella expresamente derogada).

${ }^{62}$ Cfr. H. Kelsen, Teoría general del Estado (1925), Granada, Comares, 2002, 415.

${ }^{63}$ Cfr. H. Kelsen, Teoria generale del diritto e dello Stato (1945), Milán, Comunità, 1952, 125 ss.

${ }^{64}$ Cfr. A. Merkl, "Prolegomeni ad una teoria della costruzione a gradi del diritto" (1918), en Id., Il duplice volto del diritto, Milán, Giuffré, 1987, 37 ss.

${ }^{65}$ H.L.A. Hart, The Concept of Law, cit.; N. Bobbio, "Norme primarie e norme secondarie" (1968), en Id., Studi per una teoria generale del diritto, cit. 
Además, es una idea común, aun cuando nunca explicitada, que las relaciones jerárquicas preexisten a la interpretación, de manera que los intérpretes no pueden hacer otra cosa que tomar nota de ellas ${ }^{66}$. Pero las cosas no son tan simples. Es bastante claro que algunas relaciones jerárquicas son no ya "encontradas", sino creadas por los intérpretes, mediante juicios comparativos de valor ${ }^{67}$. Este es el caso, por ejemplo, de la relación axiológica que existe -en el ámbito de un código, pongamos- entre principios fundamentales o generales y normas específicas. Este es el caso, de nuevo, de la relación entre la constitución y ciertos principios "supraconstitucionales” que, según la jurisprudencia de algunos tribunales constitucionales ${ }^{68}$, no pueden ser derogados o modificados de ningún modo: ni siquiera con el procedimiento de la revisión constitucional.

La conclusión es que no existe una única estructura jerárquica en los ordenamientos contemporáneos: hay al menos cuatro ${ }^{69}$.

(i) Jerarquía formal o estructural: entre normas sobre la producción jurídica (p. e., las normas constitucionales sobre la legislación) y normas producidas en conformidad con ellas (p. e., las normas legislativas) ${ }^{70}$.

(ii) Jerarquía material o sustancial: una primera norma A está materialmente supraordenada con respecto a una segunda norma $\mathrm{B}$, cuando una tercera norma $\mathrm{C}$ establece que $\mathrm{B}$ no puede válidamente contradecir a $\mathrm{A}^{71}$. Una constitución flexible está supraordenada a la legislación sólo en sentido formal, mientras que una constitución rígida esta supraordenada a la legislación también en sentido sustancial.

Estos dos primeros tipos de relaciones jerárquicas modelan el concepto de validez: en el sentido de que, como se ha dicho, la validez exige la con-

\footnotetext{
${ }^{66}$ Véase, sin embargo, M. Troper, "Il problema dell' interpretazione e la teoria della sovralegalità costituzionale” (1975), trad. it. en P. Comanducci, R. Guastini (eds.), L' analisi del ragionamento giuridico. Materiali ad uso degli studenti, Turín, Giappichelli, II, 1989.

${ }^{67}$ G. Tarello, “Gerarchie normative e interpretazione dei documenti normativi”, en Politica del diritto, 1977, 499 ss.

${ }^{68}$ Cfr. p. e. Corte const. it. 1146/1988.

${ }^{69}$ Cfr. R. Guastini, “Gerarchie normative”, en Materiali per una storia della cultura giuridica, 1997, 463 ss.

${ }^{70}$ Cfr. supra, § 3.1, en el punto (i).

${ }^{71}$ Bien entendido, la norma en cuestión (la norma $\mathrm{C}$ ) puede asumir las formas más diversas. Puede darse el caso de que, por ejemplo, $\mathrm{C}$ disponga que una cierta fuente $\mathrm{B}$ no puede contener normas en contradicción con otra fuente A. O bien puede darse el caso de que $\mathrm{C}$ autorice a un órgano jurisdiccional a no aplicar o directamente a anular las normas provenientes de la fuente B cuando están en contradicción con las normas provenientes de la fuente A. $\mathrm{O}$, incluso, puede darse el caso de que $\mathrm{C}$ establezca que la fuente $\mathrm{A}$ no puede ser modificada si no es con un procedimiento especial, distinto de (más complejo que) el requerido para la producción de la fuente B.
} 
formidad a las normas formalmente superiores y la compatibilidad con las normas materialmente superiores ${ }^{72}$.

(iii) Jerarquía lógica: entre normas y meta-normas (en sentido estricto $^{73}$ ). Por ejemplo: normas derogatorias y normas derogadas; definiciones legislativas y normas en cuya formulación se emplea el término definido; normas de reenvío y normas a las que se refiere el reenvío.

(iv) Jerarquía axiológica (o sea, concerniente al "valor" de las normas de que se trate): por ejemplo, entre principios y normas de detalle, entre las normas constitucionales comunes y los llamados principios constitucionales supremos $^{74}$. Pero una jerarquía de este tipo puede ser establecida (por los intérpretes) también entre un principio y otro: la solución de los conflictos entre principios constitucionales (por ejemplo, entre libertad de prensa y privacy) exige precisamente que se postule una jerarquía axiológica entre los principios en cuestión; en esto precisamente consiste la "ponderación", el "balance", de principios ${ }^{75}$.

\section{Complejidad}

(i) Podemos llamar "simple" a un ordenamiento caracterizado por una única autoridad normativa ("el soberano") y por tanto por una única fuente normativa (digamos: "la ley") ${ }^{76}$.

(ii) Podemos llamar "relativamente complejo" a un ordenamiento caracterizado por una pluralidad de autoridades normativas jerárquicamente ordenadas (por ejemplo: el Legislativo y el Ejecutivo), cada una de las cuales tiene el poder de producir fuentes de tipo distinto (por ejemplo: "Leyes” y "reglamentos") igualmente jerarquizadas"7.

(iii) Por el contrario, llamaremos "altamente complejo" a un ordenamiento caracterizado no sólo por una pluralidad de autoridades normativas jerarquizadas, sino también por una pluralidad de autoridades normativas del mismo nivel, esto es, ubicadas en el interior de un mismo grado jerárquico (por ejemplo, una pluralidad de órganos legislativos), cada una de las cuales tiene la competencia exclusiva para producir normas sobre materias

\footnotetext{
${ }^{72}$ Supra, apdo. 2.4.

${ }^{73}$ Metanorma en sentido estricto es una norma que tiene como objeto (no un acto normativo, sino) otra norma y/o la disposición que la expresa.

${ }^{74}$ Cfr. de nuevo Corte Const. it. 1146/1988.

${ }^{75}$ Cfr. R. Alexy, Teoría de los derechos fundamentales, Madrid, Centro de Estudios Constitucionales, 1993, 89 ss.; R. Guastini, L' interpretazione dei documenti normativi, cit., 216 ss.

${ }^{76}$ Cfr. H.L.A. Hart, The Concept of Law, cit., 89 ss-

${ }^{77}$ H. Kelsen, Teoria generale del diritto e dello Statu, cit., 125 ss.
} 
distintas $^{78}$. En este sentido, el ordenamiento italiano vigente tiene un carácter altamente complejo.

En un ordenamiento altamente complejo, el régimen jurídico de cada fuente del Derecho se caracteriza (entre otras cosas) por los dos rasgos siguientes:

(a) Por un lado, a cada fuente le viene asignado un ámbito de competencia material definido, de forma que esa fuente es competente para regular ciertas materias y no otras.

(b) Por otro lado, a cada fuente le viene asignada una determinada "fuerza”, o sea una peculiar ubicación en la jerarquía material del ordenamiento, de forma que esa fuente no puede contener normas incompatibles con las expresadas por fuentes supraordenadas.

\section{Sincronía y diacronía}

Evidentemente, todo ordenamiento jurídico no es tanto un conjunto de normas determinado de una vez por todas, sino más bien un conjunto de normas mutable. No obstante, un conjunto mutable no es propiamente "un" conjunto, sino más bien una sucesión de conjuntos distintos ${ }^{79}$.

De forma que un ordenamiento jurídico puede ser observado desde dos ángulos visuales distintos: el punto de vista sincrónico (o, si se quiere, estático) y el punto de vista diacrónico (o, si se quiere, dinámico $)^{80}$. Llamaremos sincrónico al punto de vista de quien observa el ordenamiento en un instante determinado de su existencia histórica, haciendo abstracción de sus cambios en el tiempo. Y llamaremos diacrónico al punto de vista de quien observa el ordenamiento en su evolución histórica. Pues bien:

(i) Bajo el perfil sincrónico, un ordenamiento se presenta como un conjunto estático de normas. Pero tal conjunto de normas está fatalmente destinado a cambiar en el tiempo: cambia cada vez que. (a) se "expulsa” del ordenamiento una norma preexistente (mediante derogación o anulación); (b) se "introduce" una norma nueva; (c) se "sustituye" una norma existen$\mathrm{te}^{81}$. De forma que:

${ }^{78}$ V. Crisafulli, “Gerarchia e competenza nel sistema costituzionale delle fonti”, en Revista trimestrale di diritto pubblico, 1960, 775 ss.; Id., Lezioni di diritto costituzionale, Padova, CEDAM, vol. II, 1984, 195 ss.; A Ruggeri, Gerarchia, competenza, e qualità nel sistema costituzionale delle fonti normative, Milano, Giuffré, 1977.

${ }^{79}$ C.E. Alchourrón, E. Bulygin, Análisis lógico y derecho, Madrid, Centro de Estudios Constitucionales, 1991, 393 ss.

${ }^{80} \mathrm{~J}$. Raz, The Concept of a Legal System. An Introduction to the Theory of Legal System, II ed., London, Oxford U.P., 1973

${ }^{81}$ Un ordenamiento jurídico visto desde el punto de vista sincrónico es, ciertamente, “un” conjunto de normas. Es, sin embargo, un "macro-conjunto”: podemos llamarlo así para subra- 
(ii) Bajo el perfil diacrónico, un ordenamiento se presenta no como un conjunto de normas, sino más bien como una secuencia dinámica de conjuntos (sincrónicos) de normas.

De esta forma, en el uso común, la locución 'ordenamiento jurídico' es ambigua ${ }^{82}$ : a veces, designa un conjunto sincrónico de normas; en otras ocasiones, designa una secuencia diacrónica de conjuntos normativos sincrónicos ${ }^{83}$.

Ahora bien, si desde el punto de vista sincrónico todo ordenamiento aparece como un conjunto "estático" de normas, desde el punto de vista diacrónico todo ordenamiento aparece por el contrario como (el resultado de) una sucesión "dinámica" de actos normativos, o sea, de actos que modifican el conjunto de normas -tal como existe en un instante dado- añadiendo, sustrayendo y sustituyendo normas. Son "actos normativos", en este sentido amplio, no sólo los actos que producen normas, sino también los actos que derogan normas o los que anulan normas (declarando su invalidez: ejemplo paradigmático, en nuestro ordenamiento, son las sentencias constitucionales "estimatorias").

\section{El carácter mixto (estático-dinámico) de los ordenamientos jurídicos}

Es pacífico que los ordenamientos jurídicos modernos tienen carácter dinámico, en el sentido que se ha dicho. Pero sería equivocado pensar que son puramente dinámicos: la verdad es que todos ellos son mixtos, es decir, estáticos y dinámicos al mismo tiempo.

Es puramente dinámico todo ordenamiento en el cual los criterios de existencia y validez de las normas son puramente "formales". Es formal todo criterio que prescinde del contenido de las normas, haciendo referencia exclusivamente al modo de producción de las propias normas (esto es, grosso modo, a la identidad del sujeto que las produce y eventualmente a

yar el hecho de que, habitualmente, los ordenamientos jurídicos son conjuntos muy amplios, constituidos por innumerables normas. Ahora bien, sucede que el ordenamiento jurídico en su totalidad, aunque sea con frecuencia objeto de especulación teórica y/o filosófica, es, sin embargo, de escaso interés para los juristas y operadores jurídicos. Estos, de ordinario, manejan conjuntos bastante más pequeños, o sea "micro-sistemas", que son subconjuntos del macroconjunto general (C.E. Alchourrón, E. Bulygin, Normative Systems, Wien, Springer, 1971).

${ }^{82}$ Para obviar esta ambigüedad, en la literatura teórico-jurídica contemporánea hay quien ha propuesto usar la expresión ‘sistema jurídico’ para designar un conjunto sincrónico de normas, y reservar la expresión ‘ordenamiento jurídico’ para designar una secuencia diacrónica de sistemas sincrónicos (C.E. Alchourrón, E. Bulygin, Análisis lógico y derecho, cit., 393 ss.; E. Bulygin, Norme, validità. Sistema normativi, cit., 231 ss.).

${ }^{83}$ J.J. Moreso, P.E. Navarro, Orden jurídico y sistema jurídico, Madrid, Centro de Estudios Constitucionales, 1993. 
los procedimientos de producción ${ }^{84}$. Pues bien, ningún ordenamiento jurídico moderno es puramente dinámico, en este sentido, al menos por dos razones:

(i) En primer lugar, todos los ordenamientos jurídicos modernos incluyen un criterio de invalidez que hace referencia al contenido de las normas ${ }^{85}$.

En virtud de tal criterio son normas inválidas no sólo las producidas de modo disconforme con las normas que regulan los procedimientos de producción de otras normas (invalidez formal), sino también aquellas que, aunque producidas “correctamente” bajo el perfil formal, son, sin embargo, incompatibles con normas jerárquicamente supraordenadas (invalidez material). Por ejemplo, en los ordenamientos con constitución rígida, es inválida toda ley que sea incompatible con la constitución; como, por lo demás, es inválido todo reglamento incompatible con la ley ${ }^{86}$.

(ii) En segundo lugar, todos los ordenamientos jurídicos modernos incluyen un criterio de validez que hace referencia al contenido de las normas.

En virtud de tal criterio son normas válidas del ordenamiento no sólo las normas “explícitas” -o sea, las normas expresamente formuladas por una autoridad normativa competente siguiendo los procedimientos apropiados- sino también todas aquellas, que, aun inexpresadas, están “implícitas” (en sentido amplio: lógico o pseudológico ${ }^{87}$ ) en las primeras ${ }^{88}$.

De forma que todos los ordenamientos jurídicos se presentan como atestados de normas inexpresadas, elaboradas por los juristas y por los órganos de aplicación, a pesar de que la doctrina y la jurisprudencia no sean fuentes “formales” del Derecho. Desde este punto de vista, la caracterización de los ordenamientos jurídicos como sistemas esencialmente dinámicos parece dejar de lado la dimensión lato sensu normativa -productora de normas- que es propia de la dogmática y de la jurisprudencia.

\footnotetext{
${ }^{84}$ H. Kelsen, Introduction to the Problems of Legal Theory (1934), Oxford, Oxford U.P., 56.

${ }^{85}$ R. Guastini, “Invalidity”, en Ratio Iuris, 1994, 212 ss.

${ }^{86}$ Mejor dicho, en verdad, si extendemos el nombre de norma también a los preceptos singulares y concretos contenidos en la parte dispositiva de las decisiones jurisdiccionales (las llamadas "normas individuales"), entonces algunas normas deben ser no sólo compatibles con las normas supraordenadas, sino deducibles sin más de una norma supraordenada, so pena de invalidez (E. Bulygin, Norme, validità, sistemi normativi, cit, 1 ss.)). Por ejemplo, en todo Estado de Derecho es inválida toda decisión jurisdiccional que no sea deducible de una norma legislativa preexistente: "En todo delito se debe hacer por parte del juez un silogismo perfecto: la premisa mayor debe ser la ley general, la premisa menor la acción conforme o no a la ley, la consecuencia la libertad o la pena” (C. Beccaria, Dei delitti e delle pene, 1764, § IV).

${ }^{87}$ Supra, § 2.2.

${ }^{88}$ R. Caracciolo, El sistema jurídico, cit., 57 ss.; E, Bulygin, Norme, validità, sistemi normativi, cit., 235 ss.
} 


\section{El ordenamiento como "sistema"}

La expresión 'ordenamiento jurídico' se usa comúnmente de forma inocente e irreflexiva, sin ningún arrière pensée: como sinónimo de "Derecho" (en sentido objetivo). Diciendo que el Derecho es ordenamiento, se trata de decir muy banalmente que el Derecho es un ordenamiento (normativo) de la conducta en cuanto “ordena”: en el doble sentido de dar órdenes y de poner orden. A veces, sin embargo, diciendo que el Derecho es un ordenamiento, se quiere decir que el Derecho es un conjunto de normas él mismo ordenado: un "sistema", o sea, una unidad consistente y coherente ${ }^{89}$.

\subsection{Coherencia}

La coherencia (coherence) exige que todas las normas pertenecientes al sistema puedan reconducirse: (a) desde el punto de vista formal, a un fundamento común de validez, o se a una sola norma última y suprema; (b) desde el punto de vista axiológico, a un único principio o a una única constelación de principios consistentes entre sí $^{90}$. A este respecto, parecen oportunas dos observaciones.

(i) Es falso, como hemos visto, que todas las normas que componen un ordenamiento sean reconducibles a un fundamento común de validez: en el sentido de que todo ordenamiento incluye, junto a las normas válidas, también normas inválidas, y asimismo normas ni válidas ni inválidas.

(ii) Pero, sobre todo, la tesis de que todas las normas existentes comparten un fundamento axiológico común ${ }^{91}$ es obviamente insostenible. Todo ordenamiento es el resultado de una gran variedad de doctrinas políticas y de políticas jurídicas, distintas y en conflicto entre sí. Y esto es verdadero incluso a nivel constitucional (aunque la constitución no sea más que un único texto normativo $)^{92}$. De otra forma, algunos conflictos entre principios consti-

\footnotetext{
${ }^{89}$ Cfr. G. Tarello, Cultura giuridica e politica del diritto, Bologna, Il Mulino, 1988, 173 SS.

${ }^{90}$ G. Zagrebelsky, Il diritto mite, cit., 34: “Cualquier ordenamiento jurídico, para ser tal y no una mera suma de reglas, decisiones y disposiciones dispersas y ocasionales, debe expresar una coherencia intrínseca, o sea debe ser reconducible a principios y valores sustanciales unitarios”. Cfr. N MacCormidk, “Coherente in Legal Justification”, en A. Peckzenik et al. (eds.), Theory of Legal Science, Dordrecht, Reidel, 1984; Id., “Coherence in Legal Justification”, en W. Krawietz et al. (eds.) Theorie der Normen. Festgabe für Ota Weinberger zum 65. Geburtstag, Berlin, 1984.

${ }^{91}$ De lo que, según Dworkin, se seguiría que toda cuestión de Derecho admite una, y sólo una, solución jurídicamente correcta. Cfr. R. Dworkin, A Matter of Principle, Cambridge (Mass.)- London, Harvard U.P., 1985, 119 ss.

${ }^{92} \mathrm{G}$. Zagrebelsky, Il diritto mite, cit., 35.
} 
tucionales -ejemplo paradigmático, entre igualdad jurídica (art. 3, 1, Const. it.) e igualdad sustancial (art. 3, 2, Const. it.)- serían inexplicables ${ }^{93}$.

\subsection{Consistencia}

La consistencia (consistency) exige algo menos que la coherencia: consiste simplemente en la carencia de antinomias, conflictos lógicos, incompatibilidades, entre normas. No obstante:

(a) Primero, las normas existentes en un ordenamiento han sido dictadas en tiempos distintos, en circunstancias distintas, por las más diversas autoridades normativas, siguiendo cada una de ellas una política jurídica propia (eventualmente en conflicto con la de otras autoridades). Tales normas no son consistentes, ni podrían serlo. Por tanto, en todo ordenamiento hay antinomias (y ello explica la existencia de esos criterios materiales de invalidez, de los que se hablaba antes ${ }^{94}$ ).

(b) Segundo, estas antinomias deben, ciertamente, ser resueltas (lo exigen el ideal de igualdad y el ideal de certeza del Derecho). Y es por esto por lo que todo ordenamiento incluye criterios de solución de antinomias, tales como "lex posterior” y "lex superior”. Pero la existencia de tales criterios no implica que el ordenamiento sea consistente: implica que puede hacerse consistente, ser “sistematizado". Ausencia de antinomias y posibilidad de resolverlas son cosas completamente distintas: el "sistema", en efecto, aparece no como un dato de hecho, preconstituido a la dogmática (a la interpretación), sino como el resultado del trabajo dogmático (interpretativo) ${ }^{95}$.

(c) Tercero, los criterios de solución de las antinomias no son susceptibles de una aplicación “mecánica”.

En primer lugar, estos criterios presuponen interpretación de los textos normativos en cuestión, puesto que sólo la interpretación puede identificar las antinomias: no hay antinomias antes de la interpretación ${ }^{96}$. Es sabido que la interpretación puede evitar las antinomias (es el caso, por ejemplo, de la interpretación adecuadora). Pero si la interpretación puede evitar las antinomias, entonces también puede crearlas ${ }^{97}$.

${ }^{93}$ Cfr. B. Celano, "Diritti, principi, e valori nello statu costituzionale di diritto: tre hipótesis di ricostruzione”, en P. Comanducci, R. Guastini (eds.), Analisi e diritto 2004. Ricercge di giurisprudenza analitica, Torino, Giappichelli, 2005, 53 ss., quien argumenta la tesis de que los conflictos entre derechos, principios y valores constitucionales son de cualquier modo inevitables.

\footnotetext{
${ }^{94}$ Supra, § 6.

${ }^{95}$ Cfr. E. Bulygin, Norme, validità, sistemi normativi, cit., 220 ss.

${ }^{96}$ Infra, § 11.3 .

${ }^{97}$ Cfr. R. Guastini, Teoria e dogmatica delle fonti,cit., 220 ss.
} 
En segundo lugar, pueden surgir antinomias de segundo grado entre los propios criterios de solución (por ejemplo, entre "lex posterior" y "lex specialis”). Sin embargo, no existe ningún metacriterio positivo para resolver todas las antinomias de este tipo ${ }^{98}$.

En tercer lugar, no hay criterios positivos para la solución de antinomias entre principios constitucionales ${ }^{99}$ (la técnica del balance o de la ponderación, comúnmente empleada por los tribunales constitucionales, no está prescrita por ninguna norma positiva, y -dicho sea de pasada-no es la única técnica posible).

(d) Cuarto, el "sistema" jurídico, en consecuencia, no es otra cosa que el fruto de la actividad sistematizadora de los juristas.

Por otra parte, se habla de ordinario de sistema jurídico para referirse al ordenamiento en su conjunto. Desafortunadamente, sin embargo, un sistema jurídico de esta guisa simplemente no existe, desde el momento en que nunca ningún jurista ha ni siquiera intentado sistematizar todo el ordenamiento. Todo jurista se ocupa únicamente de conjuntos de normas bastante más pequeños -microconjuntos- recortados, dentro de un conjunto sincrónico, con arreglo a sus intereses científicos, prácticos, o didácticos ${ }^{100}$. Son microconjuntos de normas, en este sentido, tanto el Derecho constitucional como el Derecho de las obligaciones, tanto el Derecho de los contratos como la regulación de la compraventa, tanto la regulación del arrendamiento de inmuebles urbanos para uso habitacional como el conjunto de normas relevantes para la solución de una controversia específica. El ordenamiento jurídico en su conjunto es objeto de especulación por parte de los filósofos del Derecho, pero carece de todo interés para el trabajo de los juristas.

\section{Ordenamientos centralizados y ordenamientos descentralizados}

Hay que distinguir, siguiendo a Kelsen, dos tipos de ordenamientos: ordenamientos centralizados y ordenamientos descentralizados ${ }^{101}$.

(i) Es centralizado todo ordenamiento que -como el Estado modernoinstituya órganos especializados (legislativos, ejecutivos, jurisdiccionales) para la producción y aplicación de sus propias normas ${ }^{102}$.

\footnotetext{
${ }^{98}$ Cfr. N. Bobbio, “Des critères pour résoudre les antinomies”, en Dialectica, 1964, 237 ss.

${ }^{99}$ Cfr. G Zagrebelsky, Il diritto mite, cit.

${ }^{100}$ Cfr. C. E. Alchourrón, E. Bulygin, Normative Systems, cit., 9 ss.

${ }^{101}$ H. Kelsen, Teoria generale del diritto e dello Statu, cit., 308 ss. Hago referencia aquí no a la centralización "estática” (relativa al ámbito de validez territorial de las normas), sino a la centralización '”dinámica” (relativa a los modos de producción y aplicación de las normas).

${ }^{102}$ C. Leben, "De quelques doctrines de l'ordre juridique”, cit.,
} 
(ii) Es descentralizado un ordenamiento que -como el ordenamiento internacional- confíe enteramente la producción y la aplicación de sus normas a los destinatarios de las normas mismas.

Pues bien, de acuerdo con Kelsen, todo ordenamiento centralizado es un Estado.

Este modo de expresarse, en verdad, se aleja mucho del lenguaje común, que identifica el Estado no, literalmente, con el ordenamiento, sino más bien: (a) a veces, con el conjunto de sus órganos centrales competentes para la creación y aplicación del Derechoo ${ }^{103}$; (b) otras veces, con la comunidad política subyacente ${ }^{104}$. Pero es innegable que la existencia de un ordenamiento centralizado es -también desde el punto de vista del Derecho internacional positivo- condición necesaria y suficiente para la existencia de un Estado ${ }^{105}$.

\section{Formación, contenido y extensión del ordenamiento}

Todo ordenamiento jurídico puede ser contemplado útilmente al menos desde tres distintos puntos de vista: el punto de vista de sus modalidades de formación, el de su contenido y el de su extensión.

\subsection{El modo de formación}

El Derecho -Kelsen ha insistido en ello- regula entre otras cosas también su propia creación, o sea, el modo de formación del Derecho mismo, El modo de formación del ordenamiento está establecido por un subconjunto de las normas secundarias: las metanormas que regulan la creación del Derecho, o sea, la producción de (otras) normas, confiriendo poderes

\footnotetext{
${ }^{103}$ M. Troper, "Reflexions autour de la théorie kelsenienne de l’État », en Id., Pour une théorie juridique de l'État, Paris, PUF, 1994, espec. 136. Cfr. Leben, « L'État au sens du droit international et l'État au sens du droit interne (À propos de la théorie de la double personnalité de l'État), en Studi di diritto internazionale in onore di Gaetano Arangio-Ruiz, Napoli, ESI, 2004. Bien entendido, Kelsen no es desconocedor del lenguaje común : véase, por ejemplo, lo que escribe en « L'idea del diritto naturale » (1927-1928), en H. Kelsen, Dottrina dello Stato, ed. de A. Carrino, Napoli, ESI, 1994, 126, donde distingue con inusual claridad entre "el Estado en el sentido amplio de un ordenamiento coactivo"y "el Estado en el sentido estricto de una 'organización' coactiva”.

${ }^{104}$ Pero obsérvese que es exacta la observación de Kelsen de que el ordenamiento jurídico es constitutivo de la "comunidad política", en el sentido de que lo único que liga a los miembros de la "comunidad" no es nada más que esto: su común sujeción a un mismo ordenamiento. H. Kelsen, Teoria generale del diritto e dello Stato, cit., 186 ss.

${ }^{105}$ Kelsen parece confundir la identidad ontológica (el ente A no es otra cosa que el ente B) con la equivalencia lógica (la proposición p es verdadera si, y sólo si, es verdadera la proposición q). En otras palabras, no es que Estado y ordenamiento centralizado sean "la misma cosa”, pero la proposición de que una comunidad constituye un Estado es verdadera si, y sólo si, es igualmente verdadera la proposición de que esa comunidad está gobernada por un ordenamiento centralizado.
} 
normativos y regulando su ejercicio. Tales metanormas -las "normas sobre la producción jurídica", en el léxico de la doctrina italiana ${ }^{106}$ - no son otra cosa que la "constitución material" (en uno de los muchos sentidos de esta expresión) del propio ordenamiento.

El análisis del modo de formación del ordenamiento permite distinguir entre Estados democráticos y Estados autocráticos ${ }^{107}$.

(a) Se llama democrático a un Estado en el que las normas son creadas por los mismos sujetos a quienes están dirigidas, directamente (democracia directa) o indirectamente por medio de órganos electivos (democracia representativa).

(b) Se llama autocrático a un Estado en el que las normas son creadas sin la participación de los sujetos a quienes están dirigidas.

\subsection{El contenido}

El contenido del ordenamiento jurídico está constituido por el conjunto de las situaciones jurídicas subjetivas (poderes, derechos, obligaciones, etc.) que sus normas, primarias y secundarias, establecen.

El análisis del contenido del ordenamiento es la clave para comprender la distinción entre Estado constitucional y Estado absoluto (véase el art. 16 de la Déclaration des droits de l'homme et du citoyen, 1789: "Toda sociedad en la que no esté asegurada la garantía de los derechos ni determinada la separación de poderes, no tiene Constitución”).

(i) Se llama constitucional ${ }^{108}$ a un Estado en el que: (a) el poder político (o sea, concretamente, los poderes de creación y de aplicación de las normas) está distribuido entre una pluralidad de órganos que, de acuerdo con la enseñanza de Montesquieu, se controlan y se "frenan" recíprocamente; (b) están conferidos y garantizados a los ciudadanos algunos derechos de libertad (la libertad personal, de conciencia, de reunión, de asociación, de prensa, etc.)

(ii) Se llama absoluto a un Estado que no satisfaga conjuntamente estas dos condiciones.

\subsection{La extensión}

Un ordenamiento puede ser más o menos extenso (se trata, evidentemente, de una cuestión de grado) según el número de supuestos de hecho o, desde otro punto de vista, según el número de comportamientos, que regula ${ }^{109}$.

\footnotetext{
${ }^{106}$ T. Perassi, Introduzione alle scienze giuridiche, Padova, CEDAM, 1953.

${ }^{107}$ H. Kelsen, La democracia, ed. de Barberis, Bologna, Il Mulino, 1998.

${ }^{108} \mathrm{O}$ "liberal”, en un primer sentido de esta palabra.

${ }^{109}$ H. Kelsen, La teoria politica del bolscevismo(e altri saggi), ed. de R. Guastini, Milano, Il saggiagtore, 1981, $38 \mathrm{~s}$.
} 
El análisis de la extensión del ordenamiento es la clave de la distinción entre Estados liberales y Estados totalitarios.

(i) Es liberal ${ }^{110}$ un Estado en el que sólo un área relativamente circunscrita de la conducta humana está regulada por el ordenamiento, de forma que una gran cantidad de comportamientos -especialmente los referentes a la producción y distribución de la riqueza- no está regulada y es, en ese sentido, "libre"111.

(ii) Es totalitario un Estado en el que tendencialmente todos los comportamientos humanos están sujetos a normas jurídicas.

\section{Relaciones entre ordenamientos}

Dos ordenamientos pueden mantener entre sí dos tipos de relaciones ${ }^{112}$ : independencia recíproca, o bien supraordenación-subordinación.

(a) Un ordenamiento, O1, está subordinado a otro ordenamiento, O2, cuando su norma suprema -es decir, su primera constitución- es, al mismo tiempo, una norma perteneciente a $\mathrm{O}^{113}$. Recíprocamente, un ordenamiento O2 está supraordenado a otro ordenamiento, O1, cuando incluye en sí la norma suprema de $\mathrm{O} 1$.

En otros términos, un ordenamiento subordinado no es, en rigor, un ordenamiento (independiente): es, más bien, parte de otro ordenamiento, o sea, un ordenamiento “parcial”. Un ordenamiento supraordenado, por su parte, es el ordenamiento "total” que engloba en sí al ordenamiento subordinado.

Por ejemplo, un ordenamiento regional está subordinado al ordenamiento estatal (del cual, precisamente, “forma parte”); el ordenamiento de un Estado federal está supraordenado a los ordenamientos de los Estados

\footnotetext{
110 "Liberal" en un segundo sentido de esta palabra.

${ }^{111}$ Se trata, por así decirlo, de una libertad "natural”, prejurídica: un "espacio vacío de Derecho” (K. Bergbohm, Jurisprudenz und Rechtsphilosophie, Leipzig, 1892).

${ }^{112}$ Cfr. N. Bobbio, Teoria dell'ordinamento giuridico, Torino, Giappichelli, 1960, cap. V; H. Kelsen, Teoria generale del diritto e dello Statu, cit., 378 s. Pero, para Kelsen, dos ordenamientos que no mantengan entre sí ninguna relación jerárquica, pueden únicamente ser (no ya independientes, sino) coordinados, o sea, subordinados ambos a un tercer ordenamiento. Dos ordenamientos independientes son, para él, inconcebibles desde el punto de vista de una ciencia que (como la ciencia jurídica) describa normas. Esto por la razón siguiente. Toda ciencia de normas describe normas válidas. Pero, en Kelsen, la validez no es otra cosa que la obligatoriedad o fuerza vinculante: o sea, decir que una norma es válida es decir que debe ser obedecida (paso por alto el hecho de que, así entendido, un juicio de validez no es en absoluto un enunciado descriptivo). Ahora bien, evidentemente, no pueden ser simultáneamente válidas -o sea, obligatorias- las normas pertenecientes a dos ordenamientos distintos y no relacionados (como, por ejemplo, el Derecho y la moral): si se debe obedecer a uno, no se puede obedecer al otro, y viceversa (al menos cada vez que las respectivas normas entren en conflicto).

${ }^{113}$ En el cual puede ocupar, indiferentemente, la posición de norma suprema o la posición de norma dependiente.
} 
miembros. Según la perspectiva -defendida por ejemplo por Kelsen ${ }^{114}$ - que se conoce con el nombre de "monismo", los ordenamientos estatales están subordinados al ordenamiento internacional.

(b) Dos ordenamientos, $\mathrm{O} 1$ y O2, son recíprocamente independientes cuando, banalmente, no mantienen ninguna relación de supraordenaciónsubordinación. En otras palabras: O1 es independiente de O2 si, y sólo si, su norma suprema no pertenece a O2; y, recíprocamente, O2 es independiente de $\mathrm{O} 1$ si, y sólo si, su norma suprema no pertenece a O1.

Son recíprocamente independientes, en este sentido, los distintos ordenamientos estatales ${ }^{115}$, como también, en el ámbito de un ordenamiento estatal, los diversos ordenamientos regionales ${ }^{116}$

\section{Los "problemas" del ordenamiento}

Tradicionalmente, bajo la rúbrica de "problemas" del ordenamiento se discute si los ordenamientos jurídicos son completos (o incompletos) y consistentes (o inconsistentes) ${ }^{117}$.

Se llama completo a un ordenamiento carente de lagunas.

Se llama consistente a un ordenamiento carente de antinomias.

\subsection{Lagunas}

En la doctrina, se habla de "lagunas" haciendo referencia al menos a cuatro fenómenos distintos.

(1) Lagunas normativas. Se dice que en un ordenamiento hay una laguna normativa siempre que se presente un supuesto de hecho -abstracto o concreto, según los casos- para el que ninguna norma del ordenamiento prevé una consecuencia jurídica ${ }^{118}$. Hay que decir, sin embargo, que la existencia

${ }^{114}$ H. Kelsen, Teoria generale del diritto e dello Stato, cit., 368 ss.; Id., La doctrina pura del diritto, cit., 365 ss. La tesis opuesta (“dualista”), según la cual ordenamientos estatales y ordenamiento internacional son recíprocamente independientes, es sostenida, por ejemplo, por D. Anzilotti, Corso di diritto internazionale, I. Introduzione. Teorie generali, IV ed., Padova, 1955. El problema se discute en R. Guastini, Lezioni di teoria costituzionale, Torino, Giappichelli, 2001, cap. IV.

${ }^{115}$ Según la tesis monista, a la que se ha aludido antes, los ordenamientos estatales son no ya independientes, sino coordinados (al estar todos ellos subordinados al ordenamiento internacional).

${ }^{116}$ Estrictamente hablando, diría Kelsen, los distintos ordenamientos regionales son entre ellos no ya independientes, sino coordinados (al estar todos ellos subordinados al ordenamiento estatal).

${ }^{117}$ Cfr. N. Bobbio, Teoria generale del diritto, cit., 201 ss, 237 ss.

${ }^{118}$ C.E. Alchourrón, E. Bulygin, Normative Systems, cit.

El concepto de laguna es una variable dependiente del modo de concebir las normas jurídicas. Para los que conciben las normas jurídicas como calificaciones del comportamiento ("El 
de lagunas normativas es cosa controvertida: en el sentido de que está difundida en la doctrina la teoría de que todo ordenamiento es normativamente completo y que, por tanto, las únicas lagunas existentes tienen carácter axiológico $^{119}$.

(2) Lagunas técnicas. Se dice que un ordenamiento presenta una laguna técnica cuando falta en él una norma cuya existencia es condición necesaria para la eficacia de otra norma ${ }^{120}$. Por ejemplo: una norma prescribe la convocatoria periódica de un órgano, pero ninguna norma determina qué sujeto es competente para convocarlo; una norma establece un cierto órgano electivo, pero ninguna norma establece qué sistema electoral debe adoptarse, etc. ${ }^{121}$

(3) Lagunas axiológicas. Se dice que un ordenamiento presenta una laguna axiológica (o deontológica, o ideológica, como también se suele decir) cuando un determinado supuesto de hecho -entiéndase bien- está, sí, regulado, pero está regulado de forma insatisfactoria, ya que "falta” en el ordenamiento no una norma cualquiera, sino una norma "justa" "222. ¿En qué sentido? En este contexto, por norma “justa” pueden entenderse, según las circunstancias, dos cosas sensiblemente distintas ${ }^{123}$ : o una norma que es requerida por el sentido

comportamiento x es obligatorio”, "El comportamiento y está prohibido”, "El comportamiento z está permitido, etc.), las lagunas se presentan como comportamientos no calificados. Para los que, por el contrario, conciben las normas como enunciados que conectan supuestos de hecho a consecuencias jurídicas, las lagunas se presentan como supuestos de hecho para los cuales no se encuentra dispuesta ninguna consecuencia jurídica. Este último es el punto de vista adoptado en el texto.

Las lagunas normativas no deben confundirse con las lagunas llamadas "de reconocimiento” (C.E. Alchourrón, E. Bulygin, Normative Systems, cit., 31 ss.). Grosso modo: se tiene una laguna normativa cuando hay un supuesto de hecho para el que ninguna norma dispone una consecuencia jurídica (o, dicho de otra forma, cuando un “caso” carece de solución); se tiene una laguna de reconocimiento cuando es indecidible cuál sea la consecuencia jurídica conectada a un determinado supuesto de hecho a causa de la indeterminación del lenguaje en que están formuladas las normas.

${ }^{119}$ Véase infla, el punto (3).

${ }^{120}$ A. G. Conte, Saggio sulla completezza degli ordinamenti giuridici, Torino, Giappichelli, 1962, 43 s.

${ }^{121}$ Otros ejemplos macroscópicos pueden verse en la Constitución italiana vigente: “faltan” las normas sobre la organización de la Corte constitucional y sobre el proceso constitucional (condiciones de eficacia de los artículos 134 a 137 de la Constitución: véanse las leyes constitucionales 1/1948 y 1/1953 y la ley 87/1953), “faltan” las normas sobre la constitución y el funcionamiento del Consejo superior de la magistratura (condiciones de eficacia de los artículos 104 a 107 de la Constitución: véase la ley 195/1958, varias veces modificada a continuación, hasta la ley 44/2002), etc.

${ }^{122}$ N. Bobbio, Contributi ad un dizionario giuridico, cit., $96 \mathrm{~s}$.

${ }^{123}$ Cfr. C. E. Alchourrón, E. Bulygin, Normative Systems, cit., cap VI; G. Parodi, La sentenza additiva a dispositivo generico, Torino, Giappichelli, 1996, 131 ss. 
de justicia del intérprete ${ }^{124}$, o una norma cuyo dictado es requerido por otra norma (superior) ${ }^{125}$. El punto merece algunas palabras de aclaración.

(i) En cuanto al primer caso (falta de una norma requerida por el sentido de justicia del intérprete), se puede imaginar el ejemplo siguiente. Supongamos que una disposición reconoce una consecuencia jurídica cualquiera al supuesto de hecho "daño no patrimonial" ("Si daño no patrimonial, entonces x”). El intérprete que quiera argumentar la presencia de una laguna axiológica razonará más o menos del modo siguiente. A pesar de que la disposición bajo examen, entendida literalmente, regula todo tipo de daño sin distinción, hay, si bien se mira, dos tipos bien distintos de daños no patrimoniales: los daños morales y los daños biológicos, que merecen regulaciones distintas (es esta la técnica de la "disociación" ${ }^{26}$ ). La disposición en cuestión debe pues entenderse como sujeta a una excepción implícita: "Si daño no patrimonial, a menos que se trate de daño biológico, entonces x". De forma que la consecuencia jurídica x se aplica sólo a una subclase de los daños no patrimoniales: los daños morales (interpretación restrictiva). En consecuencia, el supuesto de hecho "daño biológico" queda sin regulación: el ordenamiento es, en suma, incompleto en relación a este supuesto de hecho.

(ii) En cuanto al segundo caso (falta de una norma requerida por otra norma), se puede sostener, por ejemplo, que hay una laguna axiológica en las dos circunstancias siguientes, que constituyen casos paradigmáticos de violación del principio de igualdad (art. 3, 1 de la Constitución italiana), tal como es comúnmente entendido en la jurisprudencia constitucional: los casos iguales deben ser tratados de la misma forma, los casos distintos deben ser tratados de forma distinta ${ }^{127}$.

(a) El legislador no ha tomado en consideración una diferencia (a juicio del intérprete) "relevante" entre dos supuestos de hecho, y ha establecido

\footnotetext{
${ }^{124}$ Es esta la noción corriente de laguna axiológica (cfr. N. Bobbio, Contributi ad un dizionario giuridico, cit., 96 s.).

${ }^{125}$ Por ejemplo, el art. 81, 4 de la Constitución italiana exige que las cámaras, siempre que aprueben una norma (legislativa) que conlleve nuevos o mayores gastos respecto de los ya previstos en el presupuesto, aprueben también una norma que indique los medios para hacerles frente. El principio constitucional de igualdad (art. 3, 1, de la Constitución italiana) como veremos en seguida, puede exigir, según las circunstancias, o que el legislador aprueba una norma igualadora (en ausencia de la cual casos iguales serían tratados de formas distintas), o que el legislador apruebe una norma diferenciadora (en ausencia de la cual casos distintos serían tratados de forma igual).

${ }^{126}$ R. Guastini, L'interpretazione dei documenti normativi, cit., 163 ss.

${ }^{127}$ Los dos casos son axiológicamente equivalentes, puesto que en ambos se viola el principio de igualdad (art. 3, 1, Constitución italiana), entendido como doble obligación (a) de tratar de la misma forma supuestos de hecho iguales y (b) de tratar de forma distinta supuestos de hecho distintos.
} 
para ambos la misma regulación, omitiendo así adoptar una norma diferenciadora: de modo que a supuestos de hecho "sustancialmente" distintos se conecta una misma consecuencia jurídica.

(b) El legislador, al regular un determinado supuesto de hecho, ha omitido regular la misma forma otro supuesto de hecho, juzgado por el intérprete como "sustancialmente" igual al primero: o sea, el legislador ha omitido adoptar una norma igualadora, de modo que a supuestos de hecho "sustancialmente” iguales se conectan consecuencias jurídicas distintas ${ }^{128}$.

(4) Lagunas institucionales. Se dice, finalmente, que un ordenamiento jurídico -entendido no ya como conjunto de normas, sino como complejo de "instituciones" 129 - presenta una laguna institucional cuando, por causas de hecho, desaparece una de las instituciones que son esenciales para su funcionamiento.

Por ejemplo: se crea una laguna institucional cuando, en un Estado monárquico, se extingue la dinastía reinante, hasta que no se proceda a dar otro titular a la corona, o no se instaure una nueva forma de Estado; se crea una laguna institucional cuando una abstención persistente del cuerpo electoral impide la formación de la cámara electiva ${ }^{130}$.

En el ordenamiento constitucional italiano vigente, se produciría una laguna institucional si, por ejemplo, el Presidente de la República o las Cámaras omitieran sustituir a los jueces constitucionales, de nombramiento respectivamente presidencial y parlamentario, cesados ${ }^{131}$.

\subsection{Antinomias}

Se pueden distinguir dos tipos fundamentales de antinomias: antinomias "en abstracto" (o necesarias) y antinomias "en concreto" (o contingentes). Hablando en general, las primeras son relativamente raras; las segundas, por el contrario, son extremadamente frecuentes ${ }^{132}$.

\footnotetext{
${ }^{128}$ C. E. Alchourrón, E. Bulygin, Normative Systems, cit., 106 ss.

129 Supra, § 1.2 .

${ }^{130}$ El concepto y los ejemplos son reconducibles a S. Romano, “Osservazioni sulla completezza dell'ordinamento statale”, cit.

${ }^{131}$ Distinta es la situación que se crearía si fueran meramente derogadas (o sea, derogadas y no sustituidas), las normas que regulan la formación de un órgano constitucional. Se trataría, en este caso, no de una laguna institucional, sino de una laguna técnica (la cual, por su parte, podría generar una laguna institucional). Véase al respecto la jurisprudencia constitucional en materia de referéndum derogatorio (especialmente sentencia de la Corte constitucional 29/187).

${ }^{132}$ R. Guastini, Teoria e dogmatica delle fonti, cit., 218 s. Adviértase que las antinomias entre principios constitucionales son típicamente antinomias en concreto.
} 
(i) Antinomias en abstracto. Se tiene una antinomia "en abstracto" siempre que dos normas conectan consecuencias jurídicas incompatibles a supuestos de hecho abstractos (o sea, a clases de supuestos de hecho concretos) que se superponen (en todo o en parte) conceptualmente. De forma que la antinomia puede ser ya identificada en sede de interpretación textual, "en abstracto", sin que sea preciso imaginarse un supuesto de hecho concreto. Si, por ejemplo, una primera norma prohíbe el aborto y una segunda norma permite el aborto terapéutico, la antinomia puede ser reconocida "en abstracto", con independencia de todo supuesto de hecho concreto, desde el momento en que la clase de los abortos terapéuticos está conceptualmente incluida en la clase de los abortos sin especificaciones.

(ii) Antinomias en concreto. Se tiene una antinomia "en concreto" cuando dos normas conectan consecuencias jurídicas incompatibles para un mismo supuesto de hecho concreto, Esto sucede siempre que un supuesto de hecho concreto (o una subclase de supuestos de hecho concretos) cae simultáneamente bajo dos clases de supuestos de hecho, no obstante conceptualmente independientes, para los cuales el Derecho establece consecuencias jurídicas incompatibles. De forma que la antinomia puede identificarse sólo en sede de aplicación de las normas a un caso concreto (al cual precisamente, por casualidad, son aplicables ambas). Por ejemplo: una primera norma dispone que es obligatorio detener el coche frente a un semáforo en rojo; una segunda norma prohíbe detener el coche en las proximidades de instalaciones militares. Los supuestos de hecho regulados por las dos normas (respectivamente: "semáforo en rojo" y "proximidades de instalaciones militares") carecen conceptualmente de relación, de forma que entre las dos normas no se da, en abstracto, ninguna antinomia. Para que una antinomia se presente, sin embargo, es necesario y suficiente con que alguien tenga la poco brillante idea de ubicar un semáforo cerca de una instalación militar ${ }^{133}$.

Las antinomias en abstracto dependen, por así decirlo, de la estructura conceptual del discurso legislativo, mientras que las antinomias en concreto dependen de la estructura del mundo ${ }^{134}$.

Desde otro punto de vista, las clases de supuestos de hecho regulados por las dos normas antinómicas pueden superponerse completa o parcialmente ${ }^{135}$. Así pues, tendremos:

${ }^{133}$ J. L. Rodríguez, Lógica de los sistemas jurídicos, Madrid, Centro de Estudios Constitucionales, 2002, 93, de donde extraigo el simpático ejemplo.

${ }^{134}$ Las antinomias en cuestión tienen lugar entre dos normas "por la accidental configuración, en la realidad, de aquello sobre lo que las normas versan” (T. Mazzarese, “Antinomia”, en Digesto, IV ed., Torino, UTET, 1987).

${ }^{135}$ A. Ross, On Law and Justice, London, Stevens, 1958, 128 ss.; G. Tarello, L'interpretazione della legge, cit., 143; P. Chiassoni, La giurisprudenza civile. Metodi d'interpretazione e tecniche argomentative, Milano, Giuffré, 1999, 276 ss. 
(a) Antinomias totales. Se da superposición total cuando las dos normas conectan consecuencias incompatibles a la misma clase de supuestos de hecho. Por ejemplo, una norma califica como lícita y otra califica como ilícita la fecundación asistida.

En cuanto a la superposición parcial, puede ser de dos tipos.

(b) Antinomias parciales unilaterales. En primer lugar, puede suceder que la clase de supuestos de hecho regulada por una norma esté enteramente incluida en la clase de supuestos de hecho regulados de forma incompatible por la otra. Retomemos el ejemplo utilizado antes: una norma N1 prohíbe el aborto sin ulteriores especificaciones (o sea, toda la clase de los abortos); otra norma N2 permite el aborto terapéutico (que es una subclase de los abortos). No se da antinomia cuando están en discusión abortos no terapéuticos (prohibidos por N1), pero sí se da antinomia cuando están en discusión abortos terapéuticos, que están permitidos por N2 pero prohibidos por N1.

(c) Antinomias parciales bilaterales. En segundo lugar, puede suceder que las dos clases de supuestos de hecho se entrecrucen, de forma que algunos, pero sólo algunos, de los supuestos de hecho regulados por una norma coincidan con algunos, pero sólo algunos, de los supuestos de hecho regulados de forma incompatible por la otra. Por ejemplo, una norma N1 establece una regulación cualquiera del supuesto de hecho "reglamentos", mientras que otra norma N2 establece una regulación incompatible para el supuesto de hecho "actos ministeriales"136: no se da antinomia cuando estén en discusión actos ministeriales no reglamentarios (regulados sólo por N2), o reglamentos no ministeriales (regulados sólo por N1); pero sí se da antinomia cuando estén en discusión reglamentos ministeriales (regulados de forma incompatible tanto por N1como por N2).

\subsection{Lagunas, antinomias, interpretación}

Dicho esto, es preciso, sin embargo, aclarar que plenitud y consistencia no son propiedades, digamos, intrínsecas de un ordenamiento, previas a la interpretación. Y en tal sentido no constituyen propiamente "problemas" del ordenamiento: si se mira bien, las lagunas y las antinomias son más bien otros tantos capítulos de la teoría de la interpretación.

(i) En primer lugar, lagunas y antinomias pueden prevenirse por medio de la interpretación: en el sentido de que los textos normativos de que se trate pueden ser interpretados de forma tal que no se presente ninguna laguna ni antinomia.

\footnotetext{
${ }^{136}$ Se sobreentiende que algunos reglamentos (pero no todos) son actos ministeriales, y que algunos actos ministeriales (pero no todos) son reglamentos.
} 
(ii) En segundo lugar, lagunas y antinomias, del mismo modo que pueden ser evitadas a través de la interpretación, también pueden ser producidas a través de la interpretación: en el sentido de que los textos normativos de que se trate pueden ser interpretados de forma tal que se presente una laguna o una antinomia ${ }^{137}$.

(iii) En tercer lugar, y en consecuencia, la identificación de una laguna o de una antinomia presupone la interpretación: no se dan lagunas ni antinomias antes de la interpretación; unas y otras pueden presentarse únicamente cuando la interpretación ya ha tenido lugar.

Sin embargo, puesto que lagunas y antinomias son fruto de la interpretación o, en todo caso, lógicamente siguen -no preceden- a la interpretación, lagunas y antinomias dan lugar no propiamente a un problema interpretativo, sino a un problema de otra naturaleza. Esto por dos razones.

Por un lado, por la razón banal de que si se presenta la laguna o la antinomia, se presenta sólo cuando la interpretación ya ha sido llevada a cabo ${ }^{138}$.

Por otro lado, por la razón no banal de que para colmar una laguna es preciso integrar el Derecho, o sea, crear Derecho nuevo (pero la producción de una norma nueva, idónea para colmar una laguna, es cosa conceptualmente distinta de la interpretación de una disposición preexistente); y para resolver una antinomia es preciso eliminar una de las dos normas en conflicto (pero, de nuevo, la eliminación de una norma es cosa conceptualmente distinta de la interpretación de una disposición).

(Trad. de Manuel Atienza y Juan Ruiz Manero)

\footnotetext{
${ }^{137}$ Ejemplo paradigmático de creación interpretativa de una laguna: considérense las posibles interpretaciones del artículo 89, 1 de la Constitución italiana, que exige que los actos del Jefe del Estado sean refrendados por los "ministros proponentes". Si se entiende esta disposición en el sentido de que se refiere sólo a los actos que el Jefe del Estado lleva a cabo, precisamente, siguiendo una propuesta ministerial, se presenta una laguna: la Constitución no regula en ningún modo los actos que el Presidente lleva a cabo por su propia iniciativa (en ausencia de propuestas ministeriales). Pero, si por el contrario se la interpreta en el sentido de que se refiere a todos los actos presidenciales sin excepciones, la laguna desaparece mágicamente: ya que, desde este punto de vista, simplemente no se dan actos presidenciales que no sean precedidos de propuesta ministerial. Cfr. F. Sorrentino, "I principi generali dell'ordinamento giuridico nell'interpretazione e nell'aplicazione del diritto", en Diritto e società, 1987, 185 s.

${ }^{138}$ Bien entendido, es en sentido lógico, y no cronológico, en el que se dice que las antinomias y las lagunas "siguen” -no "preceden”- a la interpretación.
} 